\title{
Trauma from abuse, suggestibility and EMDR
}

\author{
Francesca Romana Ficorilli \\ Psicologa psicoterapeuta, criminologa clinica, terapeuta EMDR, psicodiagnosta clinica e forense, Rome, Italy
}

\begin{abstract}
One of the most complete definitions of Trauma describes it as an "extreme, unsustainable and inevitable threatening experience, in the face of which the individual experiences a sense of helplessness", an event outside the range of usual human experiences, which overwhelm the normal human capacity for adaptation. A modern and current understanding of the concept of Trauma occurs with Bowlby, which places it for the first time in a "relational" context. He argues that the way people react in adverse life situations, particularly to a traumatic event, depends on the type of attachment that has been established between the child and his attachment figures (AFs). The concept of "child abuse and neglect" includes different forms of violence against children, ranging from verbal abuse to rape. Law 66 of 15 February 1996 introduced specific rules on child sexual abuse, in particular the way of listening to children in order to collect good testimony. The theory that today represents the point of reference for most research on the accuracy of memory in testimony, considers memory a "reconstructive" process, and is the result of the interaction between interpretation that is given by the subject in the coding phase, recovery of clues based on the general knowledge possessed by the subject and the context in which it is in the moment in which it must remember. Loftus' studies on false memories affirm that eye witnessing, however bona fide it may be, can be completely unreliable because there are many distortions of memory. The problem of suggestibility in memory is not so much that the momentary account can be modified, but that a distortion of the original episode of what is represented in memory of the event in question takes place, which, from that moment on, will be irreversibly modified. The therapeutic crisis support is the first phase of the therapeutic work following the abuse and has as its privileged recipients the victim and the adult who takes care of them. Currently, a trauma-focused therapy such as EMDR (Eye Movement Desensitization and Reprocessing), an evidence-based psychotherapy approach, is used, recognized by the World Health Organization (WHO) as the elective therapy for the treatment of PTSD and several psychopathologies related to traumatic events, including sexual abuse. Not only because the victims of abuse could in turn perpetrate the cycle of abuse, but also so that victimisation is not considered an unchangeable characteristic of the person.
\end{abstract}

\section{RIASSUNTO}

Una delle definizioni più complete di Trauma lo descrive come un' “esperienza minacciosa estrema, insostenibile e inevitabile, di fronte alla quale l'individuo sperimenta un senso d'impotenza", un accadimento al di fuori della gamma delle abituali esperienze umane, che soverchiano le normali capacità umane di adattamento. Una comprensione moderna e attuale del concetto di Trauma avviene con Bowlby, che lo pone per la prima volta in un contesto "relazionale". Egli sostiene che il modo con cui le persone reagiscono nelle situazioni di vita avverse, in particolare ad un evento traumatico, dipende dal tipo di attaccamento che si è instaurato tra il bambino e le sue figure di attaccamento (FdA). Il concetto di "child abuse and neglect" include diverse forme di violenza sui minori, che spaziano dal maltrattamento verbale allo stupro. Con la Legge 66 del 15 febbraio 1996, sono state introdotte norme specifiche riguardo agli abusi sessuali sui minori, in particolare la modalità dell'ascolto protetto al fine di raccogliere una buona testimonianza. La teoria che oggi rappresenta il punto di riferimento per la maggior parte delle ricerche sull'accuratezza della memoria nella testimonianza, considera la memoria un processo "ricostruttivo", ed è il risultato dell'interazione tra interpretazione che viene data dal soggetto in fase di codifica, recupero degli indizi in base alle conoscenze generali possedute dal soggetto e contesto in cui si trova nel momento in cui deve ricordare. Gli studi della Loftus sui falsi ricordi affermano che la testimonianza oculare, per quanto in buona fede, può essere del tutto inattendibile perché intervengono numerose distorsioni di memoria. Il problema della suggestionabilità in memoria, non è tanto che possa essere modificato il resoconto momentaneo, ma che avvenga una distorsione dell'episodio originario di ciò che è rappresentato in memoria sull'evento in questione che, da quel momento in poi, sarà irreversibilmente modificato. Il sostegno terapeutico di crisi è la prima fase del lavoro terapeutico in seguito all'abuso e ha come destinatari privilegiati la vittima e l'adulto che se ne prende cura. Attualmente si impiega una terapia focalizzata sul trauma come l'EMDR (Eye Movement Desensitization and Reprocessing), un approccio psicoterapico evidence-based, riconosciuto dall'OMS come terapia elettiva per il trattamento del disturbo post traumatico da stress (PTSD - Post-traumatic stress disorder) e di diverse psicopatologie legate a eventi traumatici, tra cui l'abuso sessuale. Non solo perché le vittime di abusi potrebbero perpetrare a loro volta il ciclo dell'abuso, ma affinché la vittimizzazione non venga considerata una caratteristica immodificabile della persona.

\section{RESUMEN}

Una de las definiciones más completas del Trauma lo describe como una "experiencia extrema, insostenible e inevitablemente amenazante, frente a la cual el individuo experimenta un sentimiento de impotencia", un acontecimiento fuera del alcance de las experiencias humanas habituales, que sobrepasa la capacidad humana normal de adaptación. Una comprensión moderna y actual del concepto de Trauma ocurre con Bowlby, que lo coloca por primera vez en un contexto "relacional". Argumenta que la forma en que las personas reaccionan en situaciones adversas de la vida, en particular a un evento traumático, depende del tipo de apego que se haya establecido entre el niño y sus figuras de apego (FA). El concepto de "abuso y abandono de los niños" incluye diferentes formas de violencia contra los niños, que van desde el abuso verbal hasta la violación. La Ley $\mathrm{N}^{\circ}$ 66, de 15 de febrero de 1996, introdujo normas específicas sobre el abuso sexual de los niños, en particular sobre la forma de escuchar a los niños a fin de obtener buenos testimonios. La teoría que hoy repre- 
senta el punto de referencia para la mayoría de las investigaciones sobre la exactitud de la memoria en el testimonio, considera la memoria como un proceso "reconstructivo", y es el resultado de la interacción entre la interpretación que da el sujeto en la fase de codificación, la recuperación de pistas basadas en el conocimiento general que posee el sujeto y el contexto en el que se encuentra en el momento en el que debe recordar. Los estudios de Loftus sobre los falsos recuerdos afirman que el testimonio ocular, por muy auténtico que sea, puede ser completamente poco fiable porque hay muchas distorsiones de la memoria. El problema de la sugestionabilidad en la memoria no es tanto que el relato momentáneo pueda ser modificado, sino que se produzca una distorsión del episodio original de lo que se representa en la memoria del acontecimiento en cuestión, que, a partir de ese momento, será modificado de forma irreversible. El apoyo terapéutico en crisis es la primera fase del trabajo terapéutico posterior al abuso y tiene como destinatarios privilegiados a la víctima y al adulto que la atiende. Actualmente, se utiliza una terapia centrada en el trauma, como EMDR (Eye Movement Desensitization and Reprocessing), un enfoque de psicoterapia basado en la evidencia, reconocido por la Organización Mundial de la Salud (OMS) como la terapia electiva para el tratamiento del trastorno de estrés postraumático (PTSD - Post-traumatic stress disorder) y varias psicopatologías relacionadas con eventos traumáticos, incluyendo el abuso sexual. No sólo porque las víctimas de abuso podrían a su vez perpetrar el ciclo de abuso, sino también para que la victimización no se considere una característica inmutable de la persona.

\section{A specific trauma in developmental age: Sexual abuse}

At the state of the art, there seems to be no shared definition of child sexual abuse that finds unanimous consent among the various operators. One of the elements of discussion concerns the maximum age limit below which it is appropriate to talk about child sexual abuse. Some authors set this chronological limit at the age of 16 (Wurr and Partrige, 1996), others at the age of 18 (Russel, 1983), others at 17 (Finkelhor, 1979). As a general rule, Italian law stipulates that children under the age of 14 may not give any consent in the sexual field, except for a few special exceptions where this limit is extended to 16 years.

Another controversial aspect concerns the definition of sexual behaviour. If some acts are considered sexual in a unanimous way (vaginal and anal penetration, oral-genital contacts, exhibitionism, voyeurism), others, less invasive (think, for example, of a parent who appears naked in front of children), are not necessarily considered such and imply, for the evaluation of the case, the use of additional elements related to the context in which the episode, or episodes, occurred.

According to the American Academy of Pediatrics (1999): "Sexual abuse can be defined as a situation in which a child becomes involved in sexual activities that he or she cannot understand, for which he or she is not ready and to which he or she cannot give his or her consent and/or which violate the law or social taboos. Sexual activities may include forms of oral-genital, genital or anal contact carried out on or by the child, or non-contact sexual activities, such as exhibitionism, voyeurism or the use of the child in the production of pornographic material. Sexual abuse includes a range of activities ranging from rape to less physically intrusive forms of sexual abuse.

In a clinical setting, the term child sexual abuse refers to sexual behaviour between a child and an adult or between two children, when one of them is significantly older or uses coercion. In the latter case, it is important to consider developmental factors when assessing whether behaviour between the two children is abusive or normal. The perpetrator and the victim may be of the same or opposite sex; sexual acts may take place in a dyadic or group situation. Sexual behaviour includes touching intimate parts (with or without clothing) that the child may suffer, observe or be compelled to act on himself or herself or on others. Other sexual behaviours are: frottage, exhibitionism, voyeurism, fellatio, cunnilingus, anal or vaginal penetration by means of sexual objects or organs and pornography.

Acts of abuse are distinguished from non-abuse acts by the presence of three factors:
1. Power difference: the act is performed by a person who, by virtue of his or her role, abilities or physical characteristics, influences and controls the victim with or without the use of force.

2. Difference in knowledge: it implies that the victim has a lesser understanding of the meaning and implications of the sexual act compared to the perpetrator and that he cannot assess the implications related to the sexual act, because of his psychophysical immaturity.

3. Difference in gratification: the minor is used or exploited for the exclusive sexual gratification of the adult and finding himself in the inability to be consenting.

According to Kempe (1978), the definition of sexual abuse also includes those sexual acts that, although understood and accepted by the child, violate social taboos relating to family roles. Behaviors that can be codified as psychologically abusing, are likely to cause different outcomes depending on many factors internal and external to the child or adolescent being abused, such as: biological, personological and temperamental, emotional and environmental factors.

Emery and Laumann-Billings (1998) believe that the consequences of victimisation are, in any case, a function of at least five types of variables:

a) The nature of the abuse (beatings, verbal violence, sexual abuse, etc.), as well as its frequency, intensity and duration;

b) The nature of the relationship between victim and perpetrator (spouse, stepfather, etc.);

c) The individual characteristics of the victim (e.g. age);

d) The response of others to abuse (social support, legal or psychological intervention);

e) Abuse factors that exacerbate its effects (family chaos, entanglement).

Among the most serious forms of violence that a child can suffer, there is certainly sexual abuse, especially because it never occurs alone, but always associated with other forms of abuse, such as psychological or physical. Sexual abuse accompanied by violent acts often leads to acute states of anxiety, night terrors, interdependent behaviour, as well as phenomena of regression in development. However, sexual abuse is not always associated with physical violence: the adult often seduces the child or makes him believe that these are normal things that everyone does, especially if the child is small. The severity of the psychic damage is in no way related to the severity of the actions suffered; in fact, rape does not necessarily have more serious consequences than sexual harassment.

A distinction must be made between abuse of:

- School-age children: In cases of paedophilia, particular refer- 
ence is made to touching and exhibitionism. Some research in relation to touching (Goodman and Schwartz-Kenney, 1992) reports that most children tend not to communicate it, unless expressly asked; according to the authors, the reason is that genital contact is embarrassing, especially for older children. Other symptoms reported in relation to sexual abuse include: phobic symptoms (e.g. not wanting to leave home), obsessive symptoms (such as rituals related to personal cleansing), hysterical or psychosomatic symptoms, depression, insomnia, sudden and marked change in weight (both loss and increase), school failures resulting from emotional-relational difficulties, listlessness, escapes from home (Vassalli, 1990).

- Teenagers: in cases where the abuse consists of incest by the father, there may be demonstrations of strong rebellion against the mother, because of her absent protective function. There is evidence of anti-social behaviour, a huge drop in self-esteem (with personal experiences such as "I'm a prostitute"), social isolation, chronic depression, escapes from home. Moreover, suffering an incest in this particular life cycle of the adolescent can have an even more traumatic effect, due to the level of awareness and the implications attached to the process of identity formation (Kempe and Kempe, 1978; Vassalli, 1990).

In addition to the above, a particular symptom is the post-traumatic stress disorder (PTSD), the risk of which tends to increase when the abuse is serious and long-term and when it is consumed in a secret relationship (McLeer et al., 1992), or involves a sense of danger or guilt on the part of the child victim (Wolfe et al., 1994).

Several studies have observed that the presence of psychiatric diseases in adulthood are more frequent if the relationship between abuser and abused has continued even during adolescence and in cases where the victim is a male rather than a female (Kempe, 1980). Other research (Breslau et al., 1991) has shown that among the types of abuse, rape, in particular, involves a higher risk of PTSD than other traumas. Usually, however, the health and legislative structures are contacted only after the effects, ie in cases of pregnancy, prostitution, venereal diseases, substance abuse and antisocial behavior (Kempe and Kempe, 1978).

Ultimately, according to recent research, the modalities of implementation of "abuse and neglect of children" are distributed in four macro-categories (Kempe, 1978; Rezza, 1983, modified; in: Mastronardi V., 2011):

1. Sexual abuse, through: incest, sodomy, genital manipulation, captious caresses, exploitation of child prostitution.

2. Physical violence, manifested by: violent slap, contortion of a bone (oblique fracture), bites, scratches, beating, burns with cigarettes or through forced immersion in boiling water (palms of the hands and soles of the feet, buttocks, perineum), abrasions of the lips and tearing of the tongue frenulum (by forced nutrition), abrasions at the corners of the mouth (by gagging), various traumas to the eye and ear (by twisting), costal fractures and/or abdominal lesions, tearing off the hair.

3. Physical neglect, as a denial of care related to: nutrition, hygiene, clothing, housing, protection from hazards, medical care, prophylaxis.

4. Emotional maltreatment and neglect, by means of: abnormal and inappropriate psychological harassment, deprivation of physical contact, deprivation of direct gaze, deprivation of verbal communication "caressing", refusal to recognize (and thus improve) an emotional difficulty, an emotional disorder related to growth, a learning difficulty, emotional exploitation of the child, to be able to indirectly penalize the partner.

To these are added other minor categories, also for the low frequency, but no less significant (Kempe, 1978, Rezza, 1983, modified; in: Mastronardi V., 2011) which:
I. Emotional institutional mistreatment (nurseries, schools, institutes),

II. Mistreatment by intentional poisoning (toxic substances, barbiturates, tranquilizers, laxatives, pepper, salt, water),

III. Iatrogenic abuse and maltreatment in collaboration with the doctor and parent (tonsillectomy, phimosis, skin angiomas, torticollis of the infant),

IV. Munchausen syndrome by proxy" (simulation or induction of diseases in the child, including the administration of chemicals, such as drugs, sleeping pills and neuroleptics, but also: excess salt and water deprivation),

V. The "medical shopping by proxy" (endless and unjustified peregrinations for clinical-instrumental checks),

VI. Some narrated fairy tales (Solomon T., 1973)

Often the common belief is that many parents who sexually abuse their children have also been victims of sexual abuse; in fact, the figures report that only a third of abused children, in turn, become violent when they reach adulthood (Kaufman and Zigler, 1987; Malinowsky-Rummell and Hansen, 1993). In these cases, however, there is talk of intergenerational transmission of abuse (Emery and Laumann-Billing, 1998).

Other authors (Di Lalla and Gottesman, 1991), hypothesize that the familiarity of domestic violence may depend on a genetic rather than an environmental cause, although they consider it relevant. In relation to the medium and long term effects, Cicchetti and Toth (1995) believe that abuse incisively compromises the child's normal developmental stages in the formation of attachment bonds, in emotional regulation, in the development of self-esteem and in relations with peers, up to the persistence of relational disorders, which can result in strong distrust towards others, dysfunction of sexual behaviour, tendency to prostitution, addictive behaviour and alcoholism (Cofano and Oldani, 1993).

\section{Childhood traumatic experiences and neurobiological aspects}

The characteristics of the child's mental life and the responses evoked by the repetition of trauma, within an abusive family environment, are not fully grasped by the adultomorphic criteria of PTSD in the DSM-IV, to truly identify what is traumatic in childhood. In an effort to overcome these limits, Judith Herman proposed the definition of Post-Traumatic Complex Stress Disorder (cPTSD). By "complex traumas" the author means multiple traumatic events that repeat themselves over time, such as abuse and mistreatment, of an interpersonal nature and early onset, often within the primary care system. They differ from individual traumas, such as road accidents, an illness, natural disasters and isolated episodes of violence.

In the first years of life, relational experiences represent the primary source of knowledge that modulates genetic expression in the brain. The effect of complex trauma would seem particularly serious if it occurs during the period of maturation of the personality (Liotti, Farina 2011, 22). Since complex trauma interferes with the development of psychobiological self-regulation, adaptation to the interpersonal environment and self-image construction, it can cause, in addition to the symptoms of PTSD, also emotional regulation deficits, impulsivity, somatization, dissociation and identity alteration (Herman, 1992a).

Herman, van der Kolk and other experienced researchers in trauma-related psychopathologies, tried to promote the inclusion of the clinical picture of cPTSD within the DSM-IV, suggesting the name of Disorder of Extreme Stress Non Otherwise Specified 
(DESNOS; Extreme Stress Disorder Not Otherwise Specified, DSENAS). A series of research, epidemiological and neurobiological studies have shown that chronic interpersonal traumatic experiences, especially in childhood, produce the set of symptoms of cPTSD, supporting the theses of Herman, however the disorder has not been recognized in the DSM-IV and the symptoms found have been included only among the "symptoms associated" with PTSD in cases of childhood trauma and interpersonal type.

Herman recently revealed that the reason the American Psychiatric Association did not include cPTSD in the DSM-IV in 1994 was because it did not fit the category of anxiety disorders in which PTSD was included. Rather, as several authors and Herman herself believe, it would have been more appropriate to place it among the Dissociative Disorders or consider it as a variant of the Borderline Personality Disorder (DBP), aggravated by other dissociative and somatoform symptoms. It has long been known, in fact, that a high percentage of patients diagnosed with DBP has a history of traumatic development and a high presence of dissociative symptoms much more than in patients with the same diagnosis, but without having reported traumatic stories. It would seem logical, therefore, to place the cPTSD on Axis II instead of Axis I, like the PTSD.

According to van der Kolk (2005), multiple exposures to interpersonal trauma have predictable consequences for the development of the child in seven areas of operation:

- Attachment (difficulties of a relational type and in emotional tuning with others),

- Biological level (analgesia, medical problems in the course of life, various somatizations),

- Regulation of affection (emotional dysregulation of the self, lack of understanding of one's internal states and the other, inability to communicate needs and desires),

- Dissociation (depersonalization, alteration of the state of consciousness, amnesia),

- Control of behaviour (dysregulation of impulses, self- and hetero-aggression, opposition, substance abuse),

- Cognition (poor attentive regulation, difficulties in processing stimuli, learning difficulties and in the ability to plan and anticipate),

- Sense of self (lack of sense of self, low self-esteem, lack of sense of separateness, disturbance of body image, guilt and shame).

When referring to stable and cumulative conditions of oppressive, protracted and impossible to escape threats during childhood, such as repeated neglect and violence, the expression "traumatic development" is used. Traumatic development is the most emblematic example of complex trauma (Liotti, Farina 2011, 33).

Recently, the existence of another type of complex trauma, not recognized by the "classical" literature on PTSD, has been proposed, characteristic of the first two years of life of the child: "It would be a dysfunctional interaction between the child and his caregiver, characterized by a sort of contagion of negative emotions such as fear, which would be unconsciously and continuously expressed by the adult and "absorbed" by the child, within a relational pattern that coincides with the disorganization of attachment.

Usually, the cumulative traumas suffered by the child who develops a Traumatic Developmental Disorder (TDD), occur in the family context, or the caregivers are so vulnerable and emotionally impotent that they are unable to protect the young child, who is repeatedly traumatized by people outside the family: in this case, however, we speak of an intra-family trauma, for which the expression of neglect is used. In addition to those conditions of trauma in childhood that occur within the family context, there are others of macroscopic significance, which affect the context of the entire community in which the individual lives, represented, precisely, by the war. It is a mass traumatic event, on several occasions, in which several stressful events are repeated over time, with long-term consequences, which depends on the willingness of human actions, as in the case of refugees and displaced persons. War, as a particular traumatic event, represents a source of risk for the development of PTSD and other related disorders, such as mood disorders, somatic symptoms and externalizing and disorganized behaviors (Shaw, 2003).

Over the last thirty years, a great deal of research has been carried out to investigate children's reactions to wartime events. The protagonists of these studies come from areas devastated by conflict, such as: the Middle East, Israel and Palestine; Iraq, Iran, Kuwait; the Balkan countries, Croatia, Bosnia, Kosovo; some countries of Africa and Asia, Cambodia and Tibet. A research by Dyregrov, Gjestad, Gupta and Mukanoheli (2000) on a sample of 3030 subjects, from 8 to 19 years old, survivors of the genocide that occurred in Rwanda, showed how much the intensity and drama of exposure to war events are closely related to the relevance and frequency of post-traumatic symptoms. In this case, the multi-traumatic event consisted of having witnessed different forms of violence, injuries, murders, the death of a family member, the destruction of their home, a massacre, the vision of a corpse or parts of it. Most of the sample had to hide for several weeks, even under dead bodies.

The symptoms of PTSD in children were all the more severe as the level of exposure to trauma increased. Along with, or as an alternative to, these symptoms, the researchers found a high frequency of depressive symptoms (Macksound and Aber, 1986; Servan-Schreiber, Le Lin, Birmaher, 1998; Thabet et al, 2004) and anxious, presence of guilt, mistrust of the value of life, pessimism for the future, suicidal ideation, problems of aggression, flight from home, somatic symptoms such as dizziness, headaches, fatigue, delays in cognitive development, sleep disorders, lack of appetite (Paardekooper et al., 1999). In many of these studies the high comorbidity between PTSD and depression in children exposed to war trauma is highlighted.

Follow-ups to verify the course of the disorder between 1 and 5 years showed very high and persistent percentages of PTSD over time: from $33 \%$ to $61 \%$. These studies indicate that, even long after exposure to war events, post-traumatic symptoms in childhood tend to persist, while the intensity tends to decrease.

Although determining the variability of long-term outcomes is rather difficult, some authors such as Kuterovac-Jagodiç (2003) have observed a combination of short- and long-term predictive factors: the level of exposure to trauma would appear to be more predictive than the intensity of immediate reactions and when the disorder presents itself with a strong intensity from the beginning, the likelihood that long-term symptoms remain increases. On the other hand, factors that reduce the persistence and impact of longterm symptoms include the use of coping strategies and social support. These considerations highlight that, in addition to direct and prolonged exposure to traumatic events, risk factors and protection factors, which determine the development of symptoms over time, must be taken into serious consideration.

Numerous studies have suggested that deprivation, such as losing one's home or family, leaving one's own country or receiving less social support, accentuates the intensity of symptoms (Allwood et al., 2002; Paardekooper et al., 1999). While, a particularly supportive system for refugees (Servan-Schreiber et al., 1998), or the presence of social support (Kuterovac-Jagodiç, 2003) seem to have a determining role in reducing the severity of symptoms and their persistence.

The various studies unanimously suggest that early traumatic experiences first impact on the functioning and structure of the developing brain, with an impact on behaviour. Looking at the brain development of children with early trauma, abandonment, 
neglect, it was shown that their functioning is similar to that of children who have brain damage. In neurobiological terms, PTSD has been defined as a "physiognomy" (van der Kolk, 2003), or a disorder that manifests itself from biological emergency responses that persist over time. Under the impetus of studies related to the brain-behavior relationship, we began to investigate the biological impact of trauma with its neurobiological correlates. Currently we know that experience affects brain development, in particular, the environmental one, has a role on the differentiation of brain tissue. Early psychological trauma results not only in emotional sensitization (Maughan and Cicchetti, 2002), but also in pathological sensitization of neurophysiological reactivity (Pollak, Cicchetti, Klorman, Brumaghim, 1997).

Traumatic experiences alter the activity of the HPA axis (hypothalamus-pituitary-adrenal), a neuroendocrine system evolved in mammals for coping under threat and danger conditions. In the face of acute trauma, the survival of the individual requires an increase in cortisol, the stress hormone. In the studies on neurobiological correlates of maltreatment, there is a dysregulation of the HPA axis, which invariably detects abnormal levels of cortisol.

There are studies of the neurobiological correlates of child abuse in recent years that have led to mixed results; for example, levels below and above the controls have been found in the following parameters:

- Urinary secretion of catecholamines,

- Cardiac rhythm in response to a stressor,

- Basal cortisol secretion,

- Secretion of ACTH (adrenocorticotropic hormone).

This variability may depend on several elements: the clinical picture at the time of assessment, vulnerability factors, stress levels and the presence or absence of social support, factors related to the current stage of development. An etiopathogenetic connection was found between early experiences of abuse and maltreatment and a failure to thrive. Goldson et al. (1976) reported a positive correlation between non-accidental trauma and growth retardation in children under three years of age, with a seasonal variation in critical episodes. Often, however, it is difficult to reconstruct through which pathways, in abused children, hormonal alterations can be determined that lead to a slowing down of growth; there has been talk of endocrinological impairment of the hypothalamus-pituitary axis in response to early stressful developmental conditions.

Early puberty is reported in sexually abused prepubescent girls, probably due to exogenous activation of the sexual maturation mechanisms and the neuronal circuits related to them (Goldson et al., 1978; Montecchi, 1994).

Research has been carried out on the specific memory of traumatic experience and trauma-related information in patients with PTSD (McNally, 1991; McNally et al., 1995). The results for adult patients show that patients with PTSD tend to provide, in general, fewer autobiographical memories and, if they are stimulated to produce memories prior to the traumatic event, they more easily recall memories related to the event itself. Under conditions of strong emotional stress, children may experience significant distortions of visual and auditory perceptions, including actual hallucinations (Everson, 1997); these perceptual errors, being adapted to the child's mental patterns and expectations, end up distorting the subsequent mnestic re-enactment. In other cases, characterized by acute excitement and stress, a serious collapse of the linguistic memory system can occur, which causes traumatic events not to be integrated in a linguistic context consistent with the context of identification, but to be introduced into memory in the form of fearful associations, visual images or somatic sensations dissociated from awareness and control, as happens in the "classic" symptoms of PTSD. This kind of intrusive memories can be improperly associated with "neutral" events and stimuli, i.e. not linked to the traumatic experience and, subsequently, modify the description of the events, or lead to a generalisation of the memory of the original trauma.

Stroop's (1995) experiments on attention revealed that words closely associated with the subject's traumatic experience produce significantly greater interference than other groups of words. The results obtained in the studies on memory and attention confirm what Horowitz (1976) believed, according to which the material not completely processed (the memories related to the trauma) remains in memory in an "active" form.

The abuse is believed to be related to an alteration of cognitive development in children. Initially it was thought that the cognitive delay found in physically abused children was a direct consequence of brain trauma (Kempe, 1962; Caffey, 1972). Only a few studies have analysed the underlying psychophysiological and neuropsychological mechanisms that could play a role in determining cognitive difficulties in abused children. Lacey et al. (1962), had shown that the Autonomous Nervous System (ANS) has a role in mediating the response that can produce a facilitation or a block in the processing of information. A traumatic experience related to abuse can compromise several biophysiological systems and that the effects remain long after the trauma. Ornitz and Pynoos (1989) have shown that children with PTSD suffer a significant loss of normal inhibitory modulation of the alarm reaction, up to 21 hours after traumatic experience. Similarly, in the data collected by Carrey et al., (1995) it is inferred that experiences of physical and/or sexual abuse produce long-term cognitive effects, linked to a global inhibition of cognitive responses (both physiological and speech-mediated) following environmental stresses.

A series of publications (Bremner et al., 1995 and 1996a, b; Mc Ivor, 1997) on the involvement of different neurochemical systems in stress and PTSD, agree that a range of stressful stimuli can produce an increase in cerebral noradrenergic function at the level of the locus ceruleus, hypothalamus, hippocampus and amygdala, as well as at the level of the cerebral cortex.

Charney et al. (1993) also believe that many of the more persistent symptoms of PTSD reflect increased noradrenergic function; early exposure to stress may sensitize the individual to subsequent reactivity and further stimulation, thus constituting a risk factor for the possibility of developing PTSD. It seems, in fact, that the remarkable noradrenergic stimulation determines, in some structures of the brainstem, including the locus coeruleus, a reduction of the inhibitory cortical control, thus determining synaptic modifications that can lead to a reduced capacity of habituation to new stimuli. In practice, hyperactivation of the noradrenergic system would make the individual hypersensitive to environmental stressors, but unable to emit adequate behaviour, due to a decline in psychomotor activity and energy. These mechanisms would then predispose to the onset of depressive reactions.

On the basis of these studies, it can be assumed that experiences of abuse suffered during childhood, have the effect of raising awareness among people who have been victims, predisposing them to symptomatic sequelae pathological (PTSD, depression), following stress or trauma in adulthood. Moreover, noradrenaline seems to correlate with the consolidation of memory, defined as "inverted U-shaped": both very high and very low levels of noradrenergic activity interfere with the mechanisms of information storage. Releasing large amounts of noradrenaline, when a trauma occurs, has an important role in determining an alteration in the storage of information related to the experience in question (Keane et al., 1985; McIvor, 1997). In people with PTSD, a physiological hyperarousal may arise, mediated by the SNA, in response to a particular stimulus, if this has previously been associated with an 
unconditional stimulus, capable of activating the SNA itself, generating emotional reactions of fear or discomfort.

Other neurochemicals, such as dopamine, are also related to PTSD (Charney et al., 1993; Bremner et al., 1996a, b), which increase release in the median prefrontal cortex under stressful conditions. The prefrontal dopaminergic system is involved in a large number of high cognitive functions, such as memory and attention, so it may be involved in the state of hypervigilance that characterizes patients with PTSD. Since acute trauma or stress produces an increase in glucocorticoid levels (Charney et al., 1993), much research has measured the adverse effect of cortisol on hippocampus. The occupation of receptors by cortisol would create interference with the functioning of the hippocampus, thus suppressing the excitability of its neurons. This interferes with "long-term enhancement", considered a fundamental element of memory. Excess cortisol causes a suppression of the normal activity of a part of the brain responsible for spatio-temporal coding. This would explain why traumatic experiences seem to be "timeless and borderless".

Research data confirm that abuse experiences during the first three years of life are associated with negative biological and psychiatric effects; for example, early onset abuse is related to more significant neurobiological changes (Galvin et al., 1997; De Bellis et al., 1999 a,b). At the same time, Mc Clellan et al. noted that, on the behavioural level, children who are sexually abused in the first three years of life are four times more likely to commit child abuse in turn than children who were abused in the last years of primary school. In addition, abused children with depression can be differentiated from unabused children with the same disorder on the basis of different parameters, such as neurobiological correlates (Kaufman et al., 1998). The same authors compared a group of depressed and abused children with unabused depressed children; the first group had a significantly greater dysregulation of the serotonergic system. This dysfunction is associated with both family and experiential factors.

The volume of studies conducted so far has shown that child abuse is a specific risk factor for many psychopathological manifestations (Kaufman, 1996). In comparison to control groups, depression, self-aggressive behaviour, eating disorders, Attention with Hyperactivity Disorder (ADHD), alcoholism and substance abuse, inappropriate sexual behaviour and anti-social behaviour were more frequently found. These disorders may occur either alone or in conjunction with PTSD. However, a linear correlation between experiences of abuse and ill-treatment and the onset of specific psychopathological manifestations does not seem to be demonstrable, so much so that the notion of an "indicator" of sexual abuse is not scientifically founded.

Following his research, Constantine (1981) concluded that there is no repertoire of inevitable psychological reactions, since these are mediated by the presence of non-sexual factors. For Fergusson and Mullen (1999), it can only be demonstrated that there is an unspecific link between sexual abuse and mental health problems in adulthood, rather than a specific relationship. In addition, no specific associations between various types of abuse and particular types of disorders have been verified. Recent studies on child abuse and ill-treatment confirm that the meaning of traumatic experiences varies according to the development period in which they occurred. This would explain why similar events can lead to sequelae of even very different symptoms.

A clinical interpretative model should consider that abuse tends to compromise various areas of development, from cognitive functions to linguistic, symbolic-representative, social, emotional and interpersonal. It would be desirable to address the clinical outcomes of abuse or ill-treatment not by starting from a list of possible symptoms, but by identifying through which keys of interpre- tation certain experiences are "internalized", reaching to modify the psycho-affective organization and the ways of communicating with the external environment.

\section{Memory and testimony}

The term memory refers to very different skills: from maintaining sensory information, to remembering the meaning of words, to our wealth of knowledge and personal memories relating to our identity, as well as the planning of future actions. Memory is composed of many different interconnected systems with quite different functions, which have in common the characteristic of retaining information over time and essentially concern: the ability to process, store and retrieve information. Sometimes naive psychology is characterized by some well-founded intuition, but also by numerous erroneous beliefs. As far as memory is concerned, for example, many people are convinced that simply seeing a scene automatically involves fixing it in memory, more or less as if a photo were being taken. Sometimes, having the clear and vivid impression of owning a photographic image is well known and is part of everyone's experience; however, that there is a relationship between the impression of vividness and the actual possibility of accurately reconstructing the memory is a rather dubious probability. Certainly there can be memories that, besides being quite clear, are also quite precise, the so-called "flashbulb memories", but these, even if they exist, are an exception to the rule, which tells us, instead, that our visual memory, in fact, is normally very imprecise and is oriented only towards some elements of the overall scene (Cornoldi, De Beni, 1999). Therefore, our memory is not a faithful recorder of reality, but transforms, processes and selects information.

All the psychology of memory, perception, persuasive states, evaluation processes, emotional life, suggestive mechanisms, functions that are the basis of verbal expression, and more, combine to constitute the psychology of testimony. It must take into account the data of differential psychology, since it considers the influence that age, sex, the social environment in which the witness lives, the activities that he carries out and other factors have on the ability to testify, as well as the data of psychopathology, since it considers on the one hand the general problem of the ability to testify of subjects with particular symptomatological pictures, and on the other hand, particular morbid forms that can be the basis of the testimony.

The purpose of the psychology of testimony is to establish criteria for the evaluation and interpretation of testimonies. When it comes to judging whether an individual is sincere in giving a testimony, or whether, on the other hand, he deliberately lies, one is generally guided by certain immediate, heuristic impressions; such opinions, in turn, are often determined by subsistence, that is, by the lack of a logical connection between the various elements of the testimony; as if the fact that the witness contradicts himself, or even hints at contradicting himself, during the deposition, was an almost certain symptom of his bad faith, and instead the absence of contradictions and the fluidity of his deposition, was certainly a symptom of his sincerity.

Psychological research (Benussi, 1914), on the other hand, shows that judgments of sincerity or lies, based on these immediate impressions, are $50 \%$ of the wrong cases; therefore, for those who rely on such immediate impressions, the chances of misjudging the sincerity of a witness are equivalent to those of judging adequately. Our immediate impressions are therefore in no way usable for such a diagnosis. Thus, in the case of a witness who is a psychically healthy person, of a discreet intellectual level, honest and disinter- 
ested with respect to the fact in question, one is normally convinced that his testimony is exact, in all probability, and with respect to those details on which the witness himself declares himself certain. Yet such a belief is far from justified. From the numerous studies carried out to determine the percentage of complete and exact testimonies in all their details, which are obtained with those subjects who would appear to have all the requirements to be good witnesses, it appears that a percentage is very low. According to most authors it is only 1 or $2 \%$ (Varendonck, 1914).

If on the basis of the testimony of those who consider themselves good witnesses, we form our own opinion about the fact that it is a question of judging, this opinion will acquire in our conscience its stability and consistency, which then very hardly can be removed. Any subsequent evidence that contrasts with that opinion will necessarily be underestimated by us and there will be a tendency in us to find, for each new element that may be known about that fact, an interpretation that conforms to that opinion and even validates and consolidates it. In fact, it is a general psychological law that of our inertia in the face of the first opinions formed with respect to a given object (Musatti, 1991).

Much of experimental psychology considers memory as a variable whose functioning and characteristics are inferred from a group of observed behaviors. These behaviours are measured through three types of techniques: re-learning, re-enactment and recognition. They are quantitative techniques, as they use the number of correct answers and errors as indices of the memory size. Re-learning is a "historical" technique because it was used by Ebbinghaus (1885) in his first experimental research on memory; it consists in making the material that had been learned previously by the subject, after a certain interval of time, reappear. If the second learning reaches the same criterion as the first in a shorter time or with a smaller number of tests, it can be deduced that there was a memory of the first learning. The measure of memory is given by the percentage of time (or evidence) "saved", according to the formula:

\section{Savings $=($ Original Learning-Learning $) /($ Original Learn $) \times 100$}

This method is the most sensitive to the detection of what is present in memory, even when apparently there seems to be no memory (De Beni, 1984). The re-enactment concerns all those situations in which the subject remembers verbally. When the material is visual and the subject has to reproduce it graphically, we speak of reproduction. Verbal re-enactment can be:

A. Free: the subject can remember spontaneously without respecting an order of presentation. It may be a single trial, or, if more than one re-enactment trial is required, more than one re-enactment trial. Items that are correctly recalled are considered to be those that were presented and that appear in the re-enactment protocol. The most common errors are omissions and intrusions.

B. Serial: the material to be recalled must follow a presentation order. In addition to the errors of the free re-enactment, there are also the right items, but re-enacted in the wrong position.

C. Guided: the experimenter provides the subject with useful clues to the recovery of the material to be remembered. For example, if the item to remember is CAT, the suggestion could be the name of the category to which the item belongs (an animal), or a semantically associated term (mouse) and so on.

Of the three types of re-enactment, the guided one is the easiest and produces the highest mnestic performance, while the serial one is the most difficult. In the recognition, the subject must identify the items to be remembered that are presented to him together with others, called distractors. A task of recognition is, for example, if we are asked which of the following colours belong to the French flag: blue-green-red-white-yellow-black. A proof of recognition may be proposed in one of the following ways

1) Binary choice: one item at a time is presented to the subject, who will have to answer with a "yes" or a "no", if he believes that the item belongs, or not, to the presentation list.

2) Multiple choice: a) each item of the original list is presented together with a limited number of new items (usually 3 or 4); the subject must recognize which is the old item and discard the new ones. b) the old and the new items are presented together, mixed; the subject must always distinguish between the old and the new items.

3) Continuous: in a single list, one item is presented sequentially at a time and, from time to time, the reappearance of an item already presented is planned. The subject is asked, once again, to recognize the old items from the new ones.

In order to correctly evaluate the recognition test, it is necessary to keep in mind that the subject could give the right answer also by guessing. The probability of getting the right answer through chance increases as the number of distractors decreases. Our mnestic system is equipped to store information in a way that is functional to its use. For example, a cashier simply has to distinguish the banknotes, without dwelling on their details, or even being able to describe them. His memory system has specialized only for this purpose, achieving in it a high degree of competence and speed of execution. The cashier just needs to recognize the banknote and, to do so, he can also use partial clues, i.e. those that allow him to identify himself. In essence, the cashier would not be able to reconstruct the configuration of the banknote, but recognize it among other banknotes yes. The example cited testifies to the great difference that exists between re-enactment and recognition. These techniques involve different mental activities and lead to different amounts of memory.

Typically, recognition is easier than recall. In this condition, the subject is aware that if the answer were given to him, even in the midst of a large number of alternatives, he would be able to identify it correctly. Experimental research has confirmed, in general, the idea that recognition is simpler than re-enactment, even if there is the classic exception to the rule. This particular situation occurs when the context determines how the item is coded. That is, if a word is encoded, given the context, in a particular meaning of its uncommon use, the recovery of this word will be more difficult if it is later re-presented in another context that conveys a different meaning. This is the classical situation used by Tulving (Tulving and Thomson, 1973) in which, paradoxically, it seems easier to recall an item than to recognize it. The phenomenon is known and can be traced back to the theory of specificity, according to which an item is coded according to the context in which it is inserted. At the time of recovery, this is all the easier as the recovery context and coding context are similar. If a certain strategic key is used in the storage phase, it will be characterized as a context and it will be the use of that same key that will allow an easier finding of the memory sought. If, on the other hand, the context of recovery is very different, this may even prevent recognition of the item.

A classic distinction is that between Short Term Memory (MBT), also called Working Memory (Baddeley, 1986) and Long Term Memory (MLT), or permanent memory; the first concerns the memory of information just received and, having a limited capacity, allows to retain only a limited number of information. The second stores more stable memories, such as the vocabulary, our identity and all the knowledge and central events of our lives. The information retained in MBT will be quickly lost unless a conscious effort is made to focus our attention on it and implement a maintenance strategy, such as reiteration. However, there is much empirical evidence to support the fact that it is not the repetition, 
but the elaboration of the memorandum that produces a better memory. One of the tests cited to support the differentiation between MBT and MLT consists in the effects of serial position of words: the probability of recalling a word, is closely dependent on the position it occupied in the list. The words presented first are best remembered (phenomenon called "priority effect"), as well as the last ("recency effect"). The middle words of the list are relatively less remembered.

Patients with Korsakov Syndrome show a good memory of immediate events and a total inability to store information in the MLT. It seems, therefore, that serious MLT disorders do not involve MBT (Baddeley and Warrington, 1970). Moreover, the phenomenon whereby only one type of memory can be deficient in conjunction with intact performance in the other is called "double dissociation" and is evidence for the existence of two separate mnestic systems (Shallice, 1988). The study of the situations of incidental memory requested by Craik and Lochart (1972) and the distinction between intentional memory and incidental memory, led to the question of how the will to remember something can affect the purposes of memory. It emerged that intentionality, willingness and desire to remember something alone do not produce a better memory; their usefulness is measured by how much they induce the implementation of processes aimed at integrating the incoming information into the structures of the subject's permanent memory. If the intentional memory includes those situations that we intentionally aim to keep in our memory, in the incidental memory learning is involuntary and voluntary recovery. Specular to it is the implicit memory, in which the learning phase can be conscious, but it is the recovery that does not imply will (Schacter, 1992). An example of implicit memory is the completion of words of which only the first letters are presented, they belong, instead, to a type of explicit memory proofs of free reenactment and recognition.

To Tulving (1972) we owe the distinction between semantic memory, linked to the meaning of possessed knowledge, and episodic memory, which refers to the ability to remember individual events that occurred in a precise time and place. The study of autobiographical memory, on the other hand, is due to Galton (1883), one of the pioneers of this area, who noted that when the encoding of the word takes place within well-defined spatio-temporal coordinates and with an explicit reference to the self, this seems to produce superior mnestic performance compared to other types of encoding. Also according to Warren and colleagues (1983), autobiographical processing is such a powerful process that "the more the task elicits autobiographical memories, the better the memory will be". The explanation of the mnestic force in reference to events in one's life would depend on the fact that the self seems to be a superordinate scheme of memory of personal experience, indeed, the richest and most important scheme of memory (Keenan and Baillet, 1980). However, when recalling autobiographical memories, it is important to distinguish between vividness of memory and truthfulness, because not always the fact of remembering something in an extremely clear way is a guarantee that the memory is also true.

In addition to the now classic studies of Hunter (1957) and Loftus (1988), there is a study by Wagenaar (1988) which highlights principles and practical rules that should follow those who try to identify those guilty of criminal acts by means of eyewitnesses. Since the risk one may run is that of misunderstanding the reliability of witnesses and of recognizing the culprits of the innocent, one must always keep in mind that eyewitness testimony, even if in perfect good faith, can be completely unreliable. The Australian psychologist Donald Thomson, based on empirical data, has argued the difficulty of recognition by eyewitnesses, who would be influenced rather easily by contextual details. For example, an innocent person may be found guilty simply by wearing clothes similar to those worn by the perpetrator of a criminal act, or by being associated in another way with the crime. An erroneous recognition can happen because the victim, on the one hand, is sure not to be able to forget that face, while on the other hand has already forgotten it. This discrepancy between metacognitive belief and cognitive performance can lead to the recognition of a person already seen in other contexts associated in time or space, just as it can happen when suspects are shown in the same environment, such as the police headquarters; when they are presented several times to the witness, he will tend to recognize them, on the basis of the fact that he has already seen them and, unfortunately, also to identify them as guilty (Wagenaar, 1988).

The empirical verification of the link between emotions and memory is not easy, due to both ethical factors that prevent us from inducing strong emotions in experimental situations, and the difficulty of artificially inducing situations of authentic emotion. In one experiment, Loftus and Burns (1982) showed the film of an armed robbery, in one case presenting the scene of a heinous murder, in the other omitting it. The following memory of the details of the film was much less for those subjects who had seen the violent version. In the two films on the robbery, the intense emotion seems to induce a lesser memory, a result that is consistent with the research on eyewitness testimony (Loftus, 1979), while in a real film we see the opposite effect. In reality, the question is very complex, because even in the cases cited, the law of Yerkes and Dodson (1908) seems to apply, according to which as the level of activation (arousal) increases, the optimal performance decreases. So, in the specific case of the memory of violent scenes you might think that excessive activation is associated with a lesser memory.

In a Bartlett experiment (1932), the first subject told a story to the second, the latter told it to the third and so on. He was able to observe that the subjects operated, in memory, a reconstruction of the original story, in which the paradoxical details were eliminated and other elements added, so much so that in the end the story was modified, even though it had its own coherence. At what stages did these changes take place? In storage, during retention or during information retrieval? First of all, it can be observed that since the subjects read the story they interpret it according to their own cognitive patterns, for this reason it enters into memory already modified. According to a constructivist hypothesis, memories, besides being codified by virtue of the knowledge already possessed by the subject, therefore with a personal interpretation, would undergo further transformations with the passing of time. The results of Bransford and Franks' research (1971) show that the mnestic function tends to transform and produce new semantic units, more complete, so as to better integrate the individual elements presented. It would be plausible, therefore, that a piece already encoded in memory in a way that is congenial to the reader, undergoes further transformations in the recovery phase.

It can be concluded that the reconstruction is typical of memory and is the result of the interaction between interpretation, which is given by the subject in the coding phase, recovery of clues based on the general knowledge possessed by the subject and the context in which it is in the moment in which it must remember. In reconstructing memory, we put these data together and coordinate them so that the whole makes sense. The memory of an event is therefore one of the possible reconstructions that we make on the basis of the data available to us. A first implication of this is that even in the case of maximum accuracy, the memory is never the exact copy of the event. Only on the basis of this knowledge is it possible to get used to considering the content of a testimony as something that can never be pure photographic reproduction of an objective fact, but always the product of a multiplicity of coeffi- 
cients, which have acted in the past and which, at present, continue to act on the witness itself.

When, after a period of mnestic latency, the memory of a certain situation already experienced perceptually reappears in us, the object of our memory is profoundly modified with respect to what was the object of the initial perception. All this is commonly known. We know that with the passing of time memories fade away, that we are no longer able to intuitively represent certain details of a fact to which we have taken part or to which we have witnessed, that sometimes we are no longer even aware that the fact really belongs to our past. With regard to the transformations that things undergo in memory, we realize mostly only in a negative sense, when we lose track of it in our memory. Alongside the destruction of the mnestic material, there are real substitutions of elements, as well as mergers into a single memory, of elements belonging to distinct complexes, enrichments, etc.. And it is precisely the positive transformations of this species, suffered by our memories, that are most important for a determination of the criteria that must be taken into account in the use of testimonies.

\section{Suggestions}

The first studies on suggestibility began at the end of 1800 . Binet, Stern, Varendonck, Lipmann and MacDougall were among the first to approach this topic. Since the beginning, the study of suggestibility has been divided into two sectors: the sector of developmental psychology, in which suggestibility was studied as an individual factor or as a situational factor, and the sector of forensic psychology, in which it was analyzed as a possible source of distortion of the testimony, in particular of the testimony of the child. According to studies on the phenomenon of suggestion it is believed that manipulation of the mind does not achieve the same effects on all people, as its effectiveness seems to be modulated by the personality of the individual. Some people are very resistant to conditioning while others, vice versa, are easily influenced by others. A characteristic feature that differentiates these two types of people is the so-called "locus of control", which refers to the attribution of responsibility. If the person thinks he or she has control, then that he or she is responsible, we will say that he or she has an "internal" locus of control over his or her actions and thoughts. Vice versa, if a subject thinks he is at the mercy of external events, of destiny, of the environment in general, then we will say that he has an "external" locus of control. Individuals belonging to this second category tend to be more suggestible, indoctrinable and psychologically manipulable. In making their decisions, they rely less on their abilities and attach greater importance to external factors such as circumstances and society.

Another characteristic that distinguishes people who can be easily manipulated psychologically emerges through the construct of "dependence/independence on the field". More "dependent camp" people tend to experience circumstances in a relatively global way, passively conform to the influence of the prevailing camp or context and do not seem particularly able to separate things from the overall environment. Independent camp" people, on the other hand, tend to experience their circumstances analytically; that is, they are more able to identify objects as independent from other parties. Those who adopt a style independent of the field tend to isolate individual topics from the rest: when studying, they identify the fundamental concepts in a text and learn them without worrying about connecting them. His analytic nature makes him adept at reworking strategies. It appears more internally motivated and more flexible. Those who adopt a camp-dependent style tend to enhance the links between the topic and the context in which the topic is placed, emphasizing the relationships between individual concepts. He points out difficulties in isolating figures from contexts. There seem to be differences also with regard to the didactic activities preferred by students: dependent camp subjects prefer a type of cooperative learning, where there are continuous interactions with peers, while independent camp are more comfortable with the individual study activity.

The dependence/dependence on the field can be measured through the Embedded Figure Test (Witkin, Oltman, Raskin, Karp, 1984), in which the subject must identify in the shortest possible time, in a series of stimuli, a simple figure contained within a complex figure suitable to mask it. The test measures the ability to grasp details without being "distracted" by the complexity of the figure (analytical elaboration). Other individual differences directly related to the propensity to be manipulated are found in the level of suggestibility that in the psychological field indicates the ease with which a subject can be hypnotized. Hypnosis, as is well known, is only possible if there is collaboration from the subject who is to be hypnotized. One cannot hypnotize a subject against one's own will, as if to say that to delegate a share of power to another, a voluntary acceptance of temporary submission is necessary. A certain kind of suggestibility can easily be deduced from the degree to which a person becomes emotionally involved in reading a story or watching a film. It seems that the tendency to identify too much with emotional events makes the person more easily hypnotised and more susceptible to psychological manipulation. Atkinson (1946) distinguished three classes of suggestion, which are realized:

I. by impression, as is the case with authoritarian statements;

II. through insinuations or indirect hints, through the induction of an idea in the mind;

III. by assuming external events, which act by inducing the idea.

These three categories of suggestion reach the individual through different channels:

a) suggestion for authorities

b) suggestion for association

c) suggestion for habit

d) suggestion for repetition

e) suggestion for imitation

In his pioneering work, Binet (1900) considered the suggestibility of the witness as an indicator of hypnotic suggestibility and discovered the empirical evidence of different suggestive effects in various types of questions. In his studies he investigated the suggestibility of children between the ages of 7 and 14 years, concluding that the children gave wrong answers, accepting the information that emerged from the suggestive questions of the investigators, because they could not retrieve all the necessary information from their memory. By encountering gaps, they tried to mask them by complaining to the experimenter and accepting, in this way, the suggestions provided. Therefore, suggestibility emerged more as a social factor, that is as a form of satisfaction of the authoritarian figure, than as a cognitive factor, or mnestic difficulty. Binet's merit was to bring these experimental studies into forensic operation, recommending that judges pay attention to the way in which questions were asked of the child interviewed.

Even Stern, following his studies in the laboratory (1910), believed that there was a double mechanism behind the distorted testimony of children, on the one hand, children are imposed and the authority of the interviewer that makes them permeable to suggestive questions, on the other hand have a psychic structure that tends to confuse reality with fantasy. In particular, Stern has linked the falsity of children's testimony to the type of questions asked, holding the questioner primarily responsible for the child's report 
and urging the introduction of the figure of experts in psychological disciplines for listening to children in forensic contexts. He then demonstrated how suggestibility can depend both on the characteristics of the witness and on the characteristics of the interview. According to Stern, children are perfect observers even if they have difficulties in making their observations.

Lipmann, argued the thesis of a qualitative rather than quantitative difference between the mnestic functioning of adults and children (1911). According to the author, children and adults tend to focus their attention on different details of the same scene; this leads to different memories of each other. For this reason, if a child is interrogated by an adult, perceived by him as an authoritarian figure, he will tend to accept suggestions on those details that he has not stored, because he considers them irrelevant. As the author noted, it is difficult for children to say that they do not know or do not remember, but they tend to mix real and fantastic elements in order to provide an answer; and it is at this very moment that suggestive details are welcomed. This is what is called the misinformation effect (mentioned in the previous paragraph), also known as the "suggestibility effect", which does not refer to hypnotic suggestibility, but to the ease with which a suggested information is accepted by a witness.

Recently, researchers began to examine the characteristics of children who provide more accurate evidence than their other peers. According to these meta-analyses conducted on several studies (Bruck, Ceci, Melnyk, 1997), there is a growing consensus that the suggestibility of children requires interaction between individual characteristics and situational factors and that further research is needed to examine this relationship in detail. There are two basic types of memory errors: those that are inherent to our memory processes and those that depend on the information presented to us by others that do not belong to the original event. One speaks of suggestibility only when memory errors depend on external intervention. Sometimes, it happens that the mechanism is unaware: both information is present, that of the original event and that suggested during the interview or interview, which, however, being more recent (and thanks to this, even more accessible), is mistakenly considered part of the original memory. Or it can happen that the new information completely replaces the old one and the individual brings back in memory that only information relative to that certain event.

The problem of suggestibility in memory and misinformation is not so much that the momentary account can be modified, but rather that a distortion occurs at the level of what is represented in memory on the episode in question that, from that moment on, will be irreversibly modified (Mazzoni, 2000). There are special situations, for example when you are called as an eyewitness in a trial, where you are asked to report as accurately as possible on an event involving civil or criminal liability. Since the eyewitness is a key witness in trials, one spontaneously wonders how accurate what he reports can be. In the meantime, we know that the accuracy of the memory depends on factors such as: the nature of the event on which it is testified, what happens after the event, the individual differences between the various witnesses and the way in which the memory is recovered (i.e. whether it happens spontaneously or if it is elicited by particular interview techniques).

In the United States, psychological research into eyewitness testimony began in the late 1970 s, when the question began to arise as to whether it was possible to manipulate a memory without a person's awareness. Since, in the legal field, the credibility of the witness has a decisive influence on the process, the relevant question was whether our memories can be distorted by events that occur after the event we have witnessed. A three-step experiment was carried out in which the subjects watched videotaped scenes and immediately afterwards they were asked questions about what they had seen that contained false information. Finally, in the last phase, he was asked more questions to assess the accuracy of the memory. The crucial phase of the experiment was the second, during which being subjected to questions containing false information influenced the accuracy of the memory. This became the basis for testimony research. From then on it was considered that the accuracy of the memory of a specific event does not depend only on the accurate perception of what happened and the time interval elapsed, but also on what happens during that time interval (Pescina, 2008).

Not all people are equally suggestible; the degree to which a subject modifies the content of his own memory of the event in question is a measure of his suggestibility. The variability in the degree of suggestibility seems to depend also on demographic variables, such as age and sex; therefore children are more suggestible than adults and young children are more suggestible than adults. Instead, women and men are differently suggestible, in the sense that women are more resistant to suggestibility regarding details of female interest, while men are more resistant than details of male interest (Schooler and Loftus, 1993). The analysis of recent literature has compared a number of conflicting opinions about the greater suggestibility of children compared to adults. On the one hand, there are those who see children as susceptible, manipulable and difficult to give a valid testimony; on the other hand, there are those who consider children capable of resisting suggestion, unwilling to lie and reliable about the perception of acts considered threatening to their body integrity. The latest research focuses on paradigms in which the child actively participates in the event to be remembered and in which the situations are significant; in general, the questions asked concern central rather than peripheral details and, sometimes, suggestions precede the presentation of the event.

The sneaky aspect of the misinformation effect is that the ability to distinguish between different sources of information is zeroed out by the way the question is asked. Unfortunately, at present, there are no tools to measure the degree to which an individual who receives incorrect information will report that information as part of the original event in a subsequent interview. These measures are currently being studied (Mazzoni, in preparation), but the difficulty lies in the fact that different situations may have a different power of suggestion and that it also varies according to the personological characteristics of those who ask the questions of the interview.

Gudjonsson has developed a standardised measure of suggestibility in relation to testimony (Gudjonsson, 1992). The scale allows to have a measure of direct suggestibility, very different from the indirect one, which is at stake in the effect of misinformation. This scale measures the tendency of the witness to immediately report the version provided by the interviewer in his reply. Therefore, what emerges is not a memory effect, since a longer period of time should elapse between the question and the answer, but a "complacent" effect of the witness towards the person asking the questions. In this sense, complaisance, or direct suggestibility, leads to distortions of memory that no longer allow us to distinguish the content suggested later from the original episode.

Traditionally, suggestibility has been defined as an individual trait variable, as a person's predisposition or vulnerability to suggestive influences (Binet,1900). In the study of questionable suggestibility, two main theoretical approaches were developed: the orientation of individual differences and the experimental method (Schooler and Loftus, 1986). The approach of individual differences sees suggestibility as dependent on the coping strategies that people can generate and implement when confronted with the 
uncertainty and expectations of an interrogation situation (Gudjonsson, 1992a). In this model the emphasis is placed on the explanation of individual differences in questioning suggestibility. In the experimental approach the emphasis is on understanding the conditions under which suggestive and inductive questions are able to disrupt the witness's verbal reports (Loftus, 1979). These two approaches can be seen as complementary and uncompetitive or mutually exclusive (Schooler and Loftus, 1986).

Ceci and Bruck summarized the main theoretical positions and proposed a broader definition of suggestibility: "the degree to which children's coding, recording, retrieval and reporting of events can be influenced by a range of social and psychological factors" (Ceci and Bruck, 1993). The fact that American experimental psychologists have focused their research on the situational determinants of suggestibility, while European researchers have been concerned with suggestibility as an individual trait, could reflect the different roles of experienced psychologists in the Anglo-American accusatory system and in the continental inquisitorial system. Although in the last forty years there has been a development of at least six standardized tests (WST, TSS, SET-S, GSS, BTSS and VSSC), for the evaluation of suggestibility in the forensic field, negligence and the absence of criticism has been the attitude that most experimental psychologists have been reproached for the approach on individual differences (Endres, 1997). Numerous studies have shown that:

a. Children are more suggestible than adults.

b. The variable "authoritativeness" of the interviewer, with the risk that it entails of greater suggestibility, does not fail even when we try to eliminate this difference through the game.

c. Children aged 6-7 years are more suggestible than those aged 9 years (Mazzoni, 1997).

After almost a century of scientific research, there are now sufficient empirical data to affirm that suggestibility is caused by both cognitive and situational factors. It is due to all the factors highlighted by the research, however the relative weight of each of these mechanisms depends on the unique combination of factors that from time to time is found in the specific case (e.g., the age and cognitive abilities of the child, the nature of the memory test to which it is subjected, the mode of presentation of misinformation, and so on). All researchers who deal with the study of individual differences in children's suggestibility must absolutely recognize the mutual interaction that exists between social and cognitive processes when they interpret their experimental results.

The authors Giannini and Giusberti, reaffirm that suggestibility is a concept with many facets, involving social, communicative and cognitive processes. His relationship with age and the development stages of memory is not entirely clear. Some research shows that this is mostly confined to pre-school years, others show that suggestibility continues to decrease over preschool years, others show that it continues to decrease over the years of primary school, still others have shown that older children and adults are more suggestible than young children. The authors go on to say that "Although individuals of all ages may be suggestible, the literature generally agrees that there is an inverse relationship between vulnerability to misleading information and age, involving cognitive factors (such as information retrieval strategies, degree of understanding and the ability to monitor the source) and relational factors (such as the "authority" of the interlocutor). On the other hand, an adult who has more general knowledge than a child can be more influenced by information that, although not present in a particular circumstance, is congruent with his knowledge and experience.

However, it should also be borne in mind that the various laboratory experiments cannot account for the real involvement of the person in the moment of hypothetical abuse, which is essential to understand how emotions can affect in a powerful way, beyond any aseptic attempt at experiment and study.

\section{False memories}

Already the Greeks, like Plato and Aristotle, tried to understand, without experiments, what memory could be. In Plato's dialogues it was imagined that memory was in the world of ideas, as something metaphysical. Aristotle, on the other hand, wanted to see memory as something that could be located in something physical, such as the heart, liver, etc. Note that even today, in English, remembering by heart is called "by heart". Both, however, used models that referred to something physical, so then Plato himself, in the Teeteto, when he has to say what memory is, tries to define it as something that is engraved on a slab of wax, more or less liquid and then adds: "If then the soul is not deep or is too small and narrow, or even if it is too liquid, the imprints are mixed and overlapped and it takes a long time to find them or even it is impossible to identify them and confuse a memory with another.

Thus, the concept of false memories is delineated for which I can remember and then, at a certain point no longer remember well, because the mnemonic trace, if it is not on hard wax, on something stable, can be confused. There are various models to explain how memory works. The theory that today represents the point of reference for most research on the accuracy of memory and on the memory of testimony, considers memory as a "reconstructive" process. If memory were instead a "reproductive" process, our senses would limit themselves to passively recording the inputs and these would be stored and recovered in their original form.

According to the reconstructive model, the memory is the result of a reconstruction. Abstract and incomplete traces of the information are stored in the memory. A kind of "scheme", which contains only the essential information of the event. The complete episode is reconstructed thanks to a network of inferences relating to the "goodness" of the pieces of information that can become part of the episode in question (Mazzoni, 1999). The fragments of information that we use to reconstruct the memory, depend on the mode of execution of the processes that follow one another from when the event takes place to when we retrieve it. The three main moments of the entire mnestic process are coding, storage and retrieval. Generally, in the encoding phase the recording of those parts of the event that are selected by the subject takes place, therefore the selectivity of what is encoded reflects the limits of the person's attentive resources. The meaningfulness of the meaning and the degree of interest of the person influence the selection of the elements that become part of the memory.

There are also development differences in the evaluation of the salience of stimuli: children prefer to codify details relating to people, actions and objects that attract their interest. With development, they learn to select more important details and focus more attention on the central ones, which will be better remembered later. Of course it is difficult to form a memory on a level of insufficient understanding; this is because understanding and memory are closely interwoven skills: the more the material is processed the more it is understood, and the better it is processed the more it will be remembered. Increasing the child's knowledge is paralleled by the ease with which experiential events are understood, processed and remembered. The subject's knowledge, therefore, influences the way of interpreting the environment and the aspects that will be stored or excluded from attention. The "pieces" of the event encoded, therefore, as well as being incomplete could be 
configured as its bad reproductions if they depend on incorrect interpretations.

The central aspect of the possibility of making mistakes in the memory or remembering episodes that did not happen, depends on the fact that the reconstructive process makes it possible to insert into a memory pieces and elements that do not belong to him, such as elements that belong to another episode but that, all in all, can also fit well in the episode you are trying to remember.

It can be difficult to distinguish between episodes and therefore possible to lose information on whether a given element belongs to the original episode. Problems of recognition of the source (episode) to which a given piece of information belongs, to which one has access in memory (element), are in fact very common and seem to be present especially in young children and elderly subjects (Johnson, Hastroudi and Lindsay, 1993). During the reconstructive process that allows to arrive at a complete memory of an episode, a child can, with some ease, insert elements that belong to other moments, or parts of experiences lived by him in other periods. There is also another problem, theoretically very interesting, but at a rather serious witness level: it is possible to confuse mental contents of a different nature and origin. For example, it is possible to take as a memory what in reality was only the part of a dream (Mazzoni and Loftus, 1998), or an image (Hyman et al., 1995), the content of a story, the scenes of a video, etc. This mechanism can be one of those responsible for what happened in two famous cases of "mass abuse". The children's accusations were directed at teachers, caretakers and school staff in general. The first case occurred in Wenatchee, Washington, USA, between 1994 and 1996. A case that involved about sixty children and ten adults, all accused of having sexually abused them, repeatedly, on various occasions, in different places and by various means. Not only that, but adults were also accused of having subjected children to satanic rituals, in which other children were killed and their limbs eaten by the group, rituals also described with accuracy and abundance of detail. This case was followed by Elizabeth Loftus, a world-renowned expert in the field.

Another case in Mainz, Germany, began with a series of interviews with a child, later extended to classmates. Teachers, school caretakers and even the neighbours of the children involved were accused. After three years of court sessions, the case ended with the release of most of the defendants because the fact did not exist. Psychologist Max Steller, of the University of Berlin, followed the case and divulged a method of analysis to estimate the truthfulness of children's reports in cases of sexual abuse. In both cases, after years of trial, the allegations were not true. Having ascertained this, one wonders how it is possible for children to report non-existent episodes, remembering them with such certainty, as if they had really happened. In essence, is it possible for a person, in this case a child, to be able to construct false memories, relating to events that have not happened? A large number of researchers, mainly English-speaking, have for years concluded with certainty that it is actually possible to remember untrue events (Ceci and Bruck, 1995; Bruck, Ceci, Francoeur and Barr, 1995).

False memories would therefore be a combination of real events and suggestions not only from other people, but also from books, cinema and TV. This seems even more frequent when one is encouraged to remember certain events that in reality never happened (Pescina, 2007). Even if the "free memory" of the children, interviewed with "open questions", can be particularly accurate, a high degree of suggestibility heavily influences the quality of the memory. The researches of Ceci et al. (1987) have in fact shown that children adopt and appropriate the contents implicitly (or explicitly) suggested by adults. In one study (Garven, Wood, Malpass \& Shaw, 1998) it was shown that using techniques of reinforcement and social influence (the same used by psychologists who interrogated witness children, in the famous "McMartin case"), children told more falsehoods than they did when they only had to answer suggestive questions. In this case, therefore, even simple positive reinforcements (rewarding, praising, praising the child) and/or negative reinforcements (punishing, disapproving, etc.) have a great influence on children, so much so as to greatly influence their memories (Ceci, Loftus, Leichtman, and Bruck, 1994b).

In the judicial field, the child witness and victim of very serious facts, is often questioned several times and by several people. In a study (Clarke-Stewart et al., 1989), children were questioned by two different adults who provided false and completely opposite information about an event. The children were found to change the version of the facts based on the interviewer. Not only that, but when they later had to tell their parents about it too, they reported a set of false information obtained by the two adults, so a mixture of the two versions suggested to them.

Although it is known that the suggestion does not always completely ruin the original content of the memory of an event (Loftus, 1989), however recent works with children have shown that the suggested content can easily replace the memory of the original event. It is therefore possible to create completely false memories, especially when the memory is vague and uncertain, with various mechanisms, including making people imagine, suggesting or listening to other testimonies.

\section{Treatment of victims of sexual abuse}

After a situation of harm to a child has been identified by a team or other institution, the report to the Juvenile Court follows. The report is made when, from the collection of information, a complex of signs of discomfort emerges such as to configure a situation prejudicial to an adequate psychophysical growth of the child and to make necessary interventions of civil and/or criminal protection by the Judicial Authority. The public service operator is also obliged to report the child who is the victim of those crimes for which prosecution is required (abandonment, mistreatment, sexual violence). At this point, the psychosocial investigation requested by the Juvenile Court is carried out in the context of the civil protection of the child. If an abuse situation is detected, a series of rehabilitation interventions are provided for both the victim of the abuse and his/her family members and for the abuser.

The therapeutic crisis support is the first phase of the therapeutic work, the one immediately following the completion of the diagnostic process and has as its privileged recipients the victim and the adult who cares. The immediate objective is to transform the perception of being destroyed by one's own impotence and by the awareness that nothing can erase what has happened, into the possibility of glimpsing residual choices. It would be wrong to try to carve out a therapeutic space sheltered from the events of reality, as a purely psychic place. Urgent events can "play" instead of being an obstacle; factual tasks can be a challenge that urges one to give the best of oneself, to fund one's own resources. The second aspect to consider is that no one can succeed in such a difficult undertaking, as that of resuming to believe in life after such a collapse, if he is alone. The therapist will take the utmost care to enhance and strengthen everything that can act as an antidote to loneliness.

The first and main resource to look at is precisely the relationship between protective parent and child. The only way to achieve this is to attack the processes of denial that created distance. In order to achieve the objectives set, it will not be possible, in this phase marked by continuous emergencies, to deal with all the 
problematic nodes in an orderly manner; it will be necessary to make choices of priorities. What has been achieved with the therapeutic support of crisis is also useful to define what will be the additional objectives of the actual therapy.

Unlike other compulsive behaviours, sex offending behaviours do not in themselves contain consequences that could act as a deterrent. Those who use drugs or alcohol will end up seeing their bodies fall apart and will be able to draw, sometimes, from this, the strength to stop; but those who sexually abuse derive physical pleasure and do not record any damage in themselves: why should they stop? The only hesitation could be in feeling one's acts as psychologically dystonic: and it is here the function exerted by the mechanisms of negation that must blunt this perception before it reaches consciousness. Denial therefore has a primary quality in these subjects: it allows the abuser to perceive the perverse and upside-down world created by abuse not so much as bearable under certain conditions of high psychic cost, but as one of the possible and conceivable worlds, as long as he does not come into contact with others who instead consider it impossible and unthinkable. The therapeutic intervention for the abuser must, therefore, be articulated around these needs: to become fully aware of their own danger to the point of making the abuse unthinkable; to increase empathy, encouraging identification processes; to create an alternative way to the previous one of being active, avoiding the risk of taking refuge in passivity and irresponsibility. However, in the majority of cases, given the serious resistance of the abusers to admit their own responsibility, the only form of therapy that can be concretely practiced is that directed to families that now consist only of the victim, almost always female, and the protective parent, almost always the mother. Even if the greater investment of resources seems to translate into an individual therapy of the child, which mainly employs cognitive-behavioural and psychodynamic techniques for post-traumatic processing, and which leaves the mother a seemingly smaller space for support and accompaniment, in reality it is a therapy of the dyad.

On the other hand, if one only stops to reflect, it is not difficult to convince oneself that the mother of a small victim should be considered as a patient herself in her own right, as she is struck with the same (or even greater) violence as her traumatic child. Moreover, by bringing the child to therapy, the adult caregiver is involved in a process that knows that it will touch him closely, both for the relevance of the issues addressed, both for the degree of collaboration that is required to support the child, and finally because it is urged to tolerate and contain all the echoes that the review of post-traumatic experiences may cause in the victim. Especially in the face of this last task, the mother knows that being a spectator of her son's wounds will only be able to update her own, both in the register of the experience of guilt related to her past ineffectiveness as a protective figure, and in the register of the experience of impotence related to the narcissistic wound of having to entrust to third parties, ie the therapist, the repair of wounds too serious to provide for it with their own strength.

Often, for the parents of the victims in the case of extra-family abuse, the impact of the event is so shocking that it is of fundamental importance to provide immediate support to the family. It may happen that feelings of guilt for not being able to protect your child become so lacerating as to lead to real acting out and self-damaging punitive behaviour. Support for the child is built on the basis of emotions that are considered dangerous, whether or not you are in the presence of PTSD. Telling the daily facts and actions, current or past, positive and negative, to someone you trust, in this case to a psychotherapist expert in the development age, allows you to link emotions, thoughts and events that have occurred. Telling the full story of the abuse event makes it easier for the child to correct erro- neous attributions, such as: "I am a bad child", "I don’t have to talk about it", "You don't betray secrets". Moreover, the story as such represents an action oriented, concluded, insertable in the narrative memory of the minor and a "piece" for the reconstruction of a new self-esteem. Maintaining the skills acquired through psychotherapy depends, to a large extent, on strengthening the family and social environment. To facilitate this process, it is necessary to involve all adults significant to the child, helping them to help. Limbic regions (and in particular the orbital-frontal cortex) can remain "plastic" and, therefore, open to processes of experiencedependent maturation for the whole course of existence. An effective psychotherapeutic intervention, therefore, must be able to exploit this potential to facilitate further development of the mind. Psychotherapy can allow people with leaks or unprocessed traumas to link these aspects of memory to their past experiences and, therefore, to understand the causes of their disorders.

These reflections must take place in the context of a therapeutic relationship of secure attachment, which allows the patient's mind to encounter deeply disordered states of mind and to learn how to adapt them. A final part of psychotherapy should be dedicated to the prevention of relapses in which children and their caregivers can be prepared to cope with a risk situation that could trigger pathological mechanisms, such as reactivation of trauma. It is useful to remember that the different intervention strategies must be used in a flexible manner, respecting the needs and timescales of each child. As in the case of extra-familiar abuse, the treatment of the family is also fundamental in the intra-familiar abuse, although it involves greater difficulties. For a child, it is important that non-abuse parents, when talking about the violence they have suffered for the first time, take it seriously and believe the child's statements. It is essential that parents openly state that the responsibility for victimisation lies entirely with the abuser and that every precaution will be taken to try to protect the child in the future.

Parents should also try to understand the child's ambivalence towards the abuser, especially if it is a parental figure, such as the father. This can be very difficult to understand for the non-abuser parent, who often experiences very intense anger towards the incestuous abuser. Sometimes, the family situation is so irremediable or dangerous for his safety that it is necessary to remove the child victim of incest and place him in a foster family. This situation entails for the child the task of recognizing a parental failure, on the part of those who did not know or did not want to care for him and because of this having to process, consequently, the mourning. These children suffer numerous losses: that of a positive image of a parent (or both), that of the natural person of one or both parents in the case of a departure, that of their previous image of themselves and, finally, that of a world that was not what was hoped (Malacrea, 1998). Being able to process so many bereavements may not be easy for several reasons. First of all, in incest, elements of trauma and mourning interact that, if not recognized, distinct and treated separately, can be difficult to overcome. In fact, both trauma and bereavement present symptoms that are at least in part common, such as the re-emergence of memories, aspects of avoidance or blunting and physiological activation; for this reason it is advisable to precede the work on trauma with that on mourning (Nader, 1997).

Another difficulty arises from the fact that it is necessary for the child to recognize his or her ambivalence towards his or her parents. This process can be insidious: on the one hand it is very painful, on the other hand children have significant cognitive difficulties in understanding that they can have positive and negative feelings towards the same person, as they can concentrate on only one emotional dimension at a time (Harter, 1983).

To process memories and past experiences, you can also exam- 
ine photo albums with your child, especially with regard to people you no longer have contact with, so you can pick up the threads of a broken plot and recognize, in a more open way, in their history, both positive and negative aspects. The expression of feelings and their elaboration can be facilitated, in the case of older children or adolescents, also by writing a letter to each parent, clarifying their emotions of disappointment, betrayal, sadness, anger, etc.. The minor, through these procedures is gradually led to examine their feelings of loss and to recognize towards their parents nuances of emotional complexity in which they can converge the figure of the protector and at the same time of the executioner. The grieving process will have taken place when the minor has accepted the simultaneous presence in each person, and in particular in the parents, of positive and negative elements and has decided to rely above all on the former to eventually reset a new relationship with the parents or other reference figures.

Child victims of violence are often convinced that they are responsible for the actions inflicted on them by the abuser. When trying to change these dysfunctional beliefs, it is advisable to adopt methods that allow the child to maintain control over the events. Thus, if the child has behaved in such a way as to facilitate the continuation of the abuse, it is possible to explain to him that he is not a "bad child", but simply a "child", therefore not yet sufficiently able to make the most appropriate decisions, because he does not yet have a repertoire of strategies that can solve difficult situations such as those experienced. Moreover, after having normalized this condition, it is good to validate that the adult, being older and in possession of greater knowledge, should have controlled his own behaviour; it is therefore to him that the responsibility for his own actions should be attributed. It should also be borne in mind that victims of abuse experience paralysing feelings of guilt and shame at what has happened to them and the fear of not being believed or of being blamed by adults, often unavailable to listening and understanding, lead them to remain silent and not to be allowed to ask for help. When the abuser is a family member, there is a heated conflict between the figure of the adult as a caregiver and the representation of the same as an offender, creating an ambivalent dynamic defined by Liotti as "an unsolvable paradox" (2001; 2013), which is able to throw the child into total confusion, since it activates both the attachment system and the defence system, deeply disorganizing his Self. Usually, in these cases the victim opts to blame himself and save the caregiver.

When the subject grows up, he finds himself having to deal not only with the violence suffered, but also with strong feelings of guilt for not rebelling. Anger and shame will be directed towards oneself rather than the abuser (Shapiro, 2013). These are very resistant, complex and delicate dynamics, which must be treated with respect and caution. The burden of suffering that these children bring to therapy is very intense and it is necessary to move with appropriate modalities and times. In addition to establishing a therapeutic alliance and a climate of transparency and trust, a phase of emotional stabilization, psychoeducation about trauma and strengthening of resources is necessary before we can access traumatic memories. Precisely because the fear and pain in the trauma have been overwhelming, and often have led to dissociative and splintering defense mechanisms, it takes preparatory work for subjects to get to tolerate the emotions and feelings without being overwhelmed. As Schore and Bromberg write, the therapist becomes similar to a caregiver who is able to implement, through his right hemisphere and his relational experience, that affective regulation and subtle tuning that has been lacking or has been disturbed by violent traumatic affections; this facilitates the development and transformative process towards the awareness and integration of multiple states of the Self, of which subjectivity is formed, creating a form of "implicit relational knowledge". Another rather frequent aspect in abused children is the tendency to believe that what happened becomes something inevitable and pervasive in their lives, as no one can be trusted. This idea must be opposed, trying to direct the attention of the child on all the people with whom, in the past and in the present, he has established friendly relations and from whom he has received evidence of affection and positive interest. Another element linked to the above, which is found in victims of abuse, is the perception they have of themselves as "victims", a perception that exacerbates feelings of helplessness and inadequacy, which may worsen the risk of turning to internalizing diseases. It is therefore necessary to show them that victimisation should not be considered a definitive and unchangeable characteristic of a person: other individuals may have lived the same experience, but with the appropriate help have managed to free themselves from that experience, overcoming it. Each therapeutic treatment that aims to achieve objectives for the patient's recovery follows a gradual path to promote individual adaptive actions. One of these is to find a balance between the resources available to achieve goals and integrate one's own traumatic history into daily life.

Van der Hart presents an interesting similarity with the business world to explain the principles that should guide psychotherapeutic treatment. According to the author, as in the financial sphere, mental economy includes four simple principles based on the dynamic interaction between energy and mental efficiency. They are:

1. increase revenue, both of mental and physical energy;

2. reduce or eliminate unnecessary expenditure on mental energy;

3. reduce and eliminate debts, i.e., complete the main unfinished actions, such as emotional, relational, everyday life tasks;

4. to wisely manage the available revenues, through an increase in mental efficiency, i.e. by developing more adaptive actions and investing in them. (Van Der Hart et al. 2011, p.254).

To do this, it is important to know how to create a good relationship and a safe therapeutic framework, that is, a setting with rules defined and accepted by both parties, so as to ensure the free expression of the patient and a good reception by the therapist. A safe therapeutic relationship greatly improves the mental efficiency of the patient. According to Bowlby's attachment theory, humans function best within a secure attachment that provides the basis for interactive affection regulation. Just as every child develops important attachments with the people who care for him and every bond takes on its own physiognomy, so too in the therapeutic relationship, the psychotherapist, like a "sufficiently good" caregiver (Winnicott, 1974), offers a safe haven to the patient for his exploration, keeping the relationship within stable boundaries. Therefore, empirically confirming what the author has theorized, original parental attachments would emerge in therapy, when needs for closeness and protection due to a condition of vulnerability of the patient are activated. Particularly during the first meetings with a therapist, the patient brings the implicit and explicit effects of his trauma and attachment experiences. Whatever the nature of the first attachment relationship, it will become the basis of the attachment relationship with the therapist. In the case of MOI (Internal Operating Models) of the patient that derive from an unsafe attachment, these will affect the therapeutic relationship, determining many aspects and overwhelming the cooperative motivational system.

In addition, research shows that there is a physiological predisposition to safe attachment, so often only one safe, stable and reassuring attachment bond is sufficient to neutralize the insecure effects of the relationship with the first attachment figures (Bowlby, 1988). This has a great preventive value for children 
from traumatic experiences, socio-affective deprivation, abused or abandoned ones.

The cooperative-partisan system that is activated in therapy, defining shared objectives, is the basis of the therapeutic alliance and is facilitated only by the MOI of secure attachment. It is precisely within a therapeutic relationship based on empathic relationship, affective attunement and the ability to provide a "safe basis" that the possibility of remapping the patient's MOIs is inserted, making it possible for the patient to activate other motivational systems besides attachment (which could be dissociated), such as socialization and exploration. In the same way, the therapist's MOIs, corresponding to his attachment style, will guide the behaviour and emotions in the clinical dialogue, risking to hinder the therapeutic process, in the case of unsafe MOIs, or to favour it, representing a support network able to mitigate the deficiencies suffered, in the case of safe MOIs. Since deterministic theories alone cannot explain the different development trajectories that are outlined for each of us, it is legitimate to imagine that protective factors intervene. As Di Blasio (2005) points out, violent actions, omissions of treatment, traumas that come from adults with breeding function do not always have the same consequences. Some children seem to be able to resist, that is to say they are resilient, therefore not only able to survive, but also to face the different developmental tasks with effectiveness and competence.

Individual subjectivity is a filter that mediates the impact of the events suffered and gives each experience a personal and unique meaning. Environmental failures are not merely impressed on a passive organism, they are not always irreversible. In addition to inner resilience, an important "corrective" role is also played by the possibility of alternative affective relationships to the family, which represent an element of strength and a creative act that the minor who has grown up in the insecurity of traumatic experiences can draw on.

\section{EMDR: Desensitization and Re-processing through Eyepiece Movements}

The Eye Movement Desensitization and Reprocessing (EMDR) is a therapeutic method, the birth of which can be traced back to a random observation that Francine Shapiro made in 1987; one day, while walking in a park, she noticed that some disturbing thoughts that she had suddenly disappeared. He observed that when he returned with his mind to those thoughts they were no longer disturbing and present as before. He had noticed that those disturbing thoughts have a certain "cycle": that is, they tend to manifest themselves continuously until something is consciously done to stop or change them. Fascinated by what was happening, she saw that when the disturbing thoughts came back to her mind, her eyes spontaneously began to move back and forth in a diagonal line.

Again the thoughts disappeared and when he brought them back to mind their negative charge had greatly diminished. He then began to deliberately perform eye movements as he concentrated on various disturbing thoughts, realizing that these thoughts also disappeared and lost their emotional charge. Feeling his wonder grow, he began to glimpse the potential benefits of this effect. EMDR was born as a specific therapy for the treatment of people with PTSD, and at present scientific research has established that it is an empirically supported and evidence-based approach to the treatment of Post-Traumatic Stress Disorder. The effectiveness of EMDR is not limited to trauma as defined by the DSM, i.e. "the individual has experienced, witnessed or been confronted with a potentially fatal event, life-threatening or seriously injured, or a threat to his or her physical integrity or that of others; the individual's response includes intense fear, vulnerability or horror". On the contrary, its effectiveness is also demonstrated for all negative experiences which, although not falling within this definition, are stressful or generate, in any case, post-traumatic symptoms.

The theoretical assumption of EMDR is that any current dysfunctional reaction (except pathologies with an organic or chemical basis) is always the result of a previous experience, not necessarily a childhood one. EMDR is a patient-centred approach in which the therapist acts as a facilitator of his or her self-healing process. Looking through the prism of the EMDR offers a new way of seeing the disease: as stored information. Mnemonic networks are seen as the basis underlying pathology and mental health. During the experience of a traumatic event, the biochemical responses it elicits (adrenaline, cortisol, etc.) would block the innate brain system of information processing, leaving isolated in a neurobiological stasis the information related to the trauma, trapped in a neural network with the same emotions, beliefs and physical sensations that existed at the time of the event. From this perspective, the disease would occur when this innate system freezes and the traumatic event does not integrate with the rest of the autobiographical experience, according to a coherent and fluid narrative.

Exposure to stressful events plays a fundamental role in the onset of many psychopathologies, especially if there are psychosocial factors and genetic vulnerability and inborn, as argued by the theory of multifactorial origin of mental disorders. Metabolic, neuroendocrine and autonomic changes resulting from stress are regulated by a balance that may already be disturbed by early experiences of abuse and would lead to the development of a disorder over the years. Brain circuits develop in ways directly linked to their activation. Our experiences can therefore significantly influence the neural connections and the organisation of our brain activities and for this reason the experiences that occur during the first years of life and traumas play a particularly important role (Siegel, 2002). The concept that trauma in itself in some way causes imbalance that prevents proper processing was presented by Janet (1889/1973) and Pavlov (1927) and has been reiterated in contemporary studies on the effects of neurotransmitters (van der Kolk, 1994; Watson, Hoffman and Wilson, 1988; Zager and Black, 1985). Moreover, the hypothesis that the same traumatic information moves to a positive plateau, once the system is activated, is derived from the constant observation of EMDR therapeutic sessions.

Experience shapes the brain through neuroplasticity, i.e. the connections of the brain change and this changes the brain itself. The way neural connections occur determines how the brain functions. Since, as we learn, new synaptic connections are constantly being formed, it comes naturally to us that a good psychotherapeutic path represents an opportunity for enormous experiential growth. The objective of EMDR is to move, especially through bilateral stimulation, the information processing system to transform stored perceptions in a dysfunctional way.

Once the old memories and current stimuli have been properly resolved, it is important to explore the ways in which the patient would like to be able to perceive, feel, behave and what he would like to believe in the present and the future. Once the patient has been given adequate instructions and tools (e.g. on assertiveness, social rights and rules or other skills), he will be asked to imagine the optimal behavioural responses, together with a Positive Cognition that will enhance him/herself. The therapist will therefore lead the patient through successive sets of Eyepiece Movements (MO), to assist him/her in assimilating the information and in inserting this information into the framework of the future perspective, for the action to come. The patient imagines an adaptive response in the future and mentally flows through a film of the 
future in which he meets a person, a situation, is in a place or takes any specific action that was previously a source of disturbance. The goal is to address avoidance, adaptation and realization.

Sometimes, failures in target processing often depend on additional blocking beliefs; these may be processed spontaneously or may require to be treated as targets in turn, separately. Patients, even if adequately prepared with a "psychoeducation" to the treatment, may often present fears; e.g., to go crazy, to relive certain emotions related to the trauma, to change, to lose respect for the therapist, or to make disappear the beautiful memories related to someone whose trauma of mourning is elaborating. With some of them, integrated cognitive intervention, the use of deceleration or distance strategies can be very useful. Even if a patient presents an abreaction (i.e. high levels of emotional stress) the therapist will consider how to adapt a different strategy in such a way as to be supportive and maintaining the patient's awareness of a double focus: in the past and in the present.

Abreaction is a high intensity emotional discomfort that can occur when the patient "re-experiences" a part of a life experience during the EMDR session. Most of the time, abreaction occurs as the information is processed; it does not consist in a re-traumatization of the disturbing experience. The therapeutic work goes back and forth, we work on the most ancient traumas, up to the most recent ones, after the triggers, but without forgetting, however, that for various reasons, not all traumatized patients can progress beyond stabilization. It is therefore important to make stabilization a prerogative of care, since the challenge is to find the right balance between the work in progress in stabilizing the patient and the work of desensitization to process traumatic memories. A sufficiently strong therapeutic alliance is the basis on which to base the rest; what matters later is how to integrate EMDR into the therapeutic process.

\section{References}

Allwood M. A., Bell-Dolan D., Husain S. A., (2002), Children's trauma and adjustment reactions to violent and nonviolent war experiences. Journal of the American Academy of Child and Adolescent Psychiatry, 41, pp. 450-457.

APA, (1994), Diagnostic and Statistical Manual of Mental Disorders IV (4th ed.). Washington DC: American Psychiatric Association. Trd. It. DSM-IV Manuale diagnostico e statistico dei disturbi mentali, Masson, Milano.

APA, (2014), Diagnostic and Statistical Manual of Mental Disorders V (5th ed.). Washington DC: American Psychiatric Association. Trd. It. Criteri diagnostici Mini DSM-5, Raffaello Cortina Editore, Milano.

Baddeley, A. D., (1986), Working memory, Oxford University Press, Oxford.

Baddeley A. D., \& Warrington E., (1970), Amnesia and the distinction between long and short-term memory. Journal of Verbal Learning and Verbal Behaviour, 14, pp. 575-595.

Bartlett F., (1932), Remembering: A Study in Experimental and Social Psychology, Cambridge University Press, UK.

Binet A., (1900), La suggestibilité, Schleicher Freres, Paris.

Bowlby J., (1969), Attachment and loss. I: Attachment, Hogart Press, London. Trad. it. Attaccamento e perdita. Vol. I: Attaccamento alla madre, Boringhieri, Torino.

Bowlby J., (1973), Attachment and loss. II: Anxiety and Anger, Hogarth Press, London. Trad. it. La separazione dalla madre. Vol. II, Boringhieri, Torino.

Bowlby J., (1980), Attachment and loss. III: Loss, Sadness and
Depression, Hogart Press, London. Trad. it. Attaccamento e perdita. Vol. III: La perdita della madre, Boringhieri, Torino.

Bowlby J., (1988), A secure base: Parent-child attachment and healthy human development, Basic Books New York. Trad. It. Una base sicura, (1989), Raffaello Cortina Editore, Milano.

Benussi V., (1914), Review of Ko.f.lka-Kenkel 'Beitrilge zur Psychologie der Gesta/t und Bewegungserlebnisse. In Archiv fiir die gesamte Psychologie, 32, pp. 50-7.

Bremner J.D., Krystal J. H., Southwick S. M., Charney D. S., (1996a), Noradrenergic mechanisms in stress and anxiety: I. Preclinical studies. Synapse; 23: 28-38.

Bremner J. D., Krystal J. H., Southwick S. M., Charney D. S., (1996b), Noradrenergic mechanisms in stress and anxiety: II. Clinical studies. Synapse; 23: 39-51.

Bremner J. D., Randall P., Scott T. M., Bronen R. A., Seibyl J. P., Southwick S. M., Delaney R. C., McCarthy G., Charney D. D., Innis R. B., (1995), MRI-based measurement of hippocampal volume in patients with combat-related posttraumatic stress disorder. American Journal of Psychiatry, 152, pp. 973-98.

Breslau N., Davis G. C., Andreski P., Peterson E., (1991), Traumatic events and posttraumatic stress disorder in an urban population of young adults. Arch Gen Psychiatry, (Mar); 48(3): 216-22.

Bruck M., Ceci S., Francouer E., Barr R. J., (1995), I hardly cried when I got my shot. Influencing children's report about a visit to their pediatrician, Child Development, 66, pp. 193-208.

Bruck M., Ceci S., Melnyk L., (1997), External and internal sources of variation in the creation of false reports in children. In Learning and Individual Differences, 9, pp. 289-316.

Caffey J., (1972), On the theory and practice of shaking infants. Its potential residual effects of permanent brain damage and mental retardation. American Journal of Diseases of Children, 124, 161-169.

Ceci S. J. \& Bruck M., (1993), Suggestibility of the child witness: A historical review and synthesis. Psychological Bulletin, 113, pp. 403-439.

Ceci S. J., Loftus E. F., Leichtman M., \& Bruck M., (1994), The possible role of source misattribution in the creation of false beliefs among preschoolers. International Journal of Clinical and Experimental Hypnosis, 42, pp. 304-320.

Cofano C., Oldani M., Poli M. D. (1993), Il maltrattamento infantile: percezione del fenomeno da parte dei pediatri e dei medici scolastici di Milano e provincia. Ricerche di Psicologia, vol. 17, n.1, pp. 53-74.

Charney D. S., Deutch A. Y., Krystal J. H., Southwick S. M., Davis M., (1993), Psychobiologic mechanisms of posttraumatic stress disorder, Arch Gen Psychiatry, (Apr); 50(4): 295-305.

Constantine L. L., (1981), The effects of early sexual experience: A review and syntesis of research. In Constantine L., Finkelhor D. (1979), Sexually victimized children, Free Press, New York.

Cornoldi C., De Beni R., (1999), Basic computation and strategic control in the use of mental imagery, Cahiers de Psychologie CognitiveCurrent Psychology of Cognition, vol. 18, 4, pp. 495-501.

Craik F. I. M., \& Lockhart R. S., (1972), Levels of processing: A framework for memory research. Journal of Verbal Learning and Verbal behavior, 11, pp. 671-684.

De Bellis M. D., Baum A., Birmaher B., Keshavan M., Eccard C. H., Boring A. M., Jenkins F. J., Ryan N. D., (1999a), Developmental traumatology part I: biological stress systems. Biol. Psychiat. 45, pp. 1259-1270.

De Bellis M. D., Keshavan M., Clark D. B., Casey B. J., Giedd J., Boring A. M., Frustaci K., Ryan N., (1999b), Developmental traumatology part II: brain development. Biol. Psychiat. 45, pp. 1271-1284.

Di Blasio P., (2005), (a cura di), Tra rischio e protezione. La 
valutazione delle competenze parentali, Edizioni Unicopli, Milano, p. 26.

Di Lalla L. F., \& Gottesman I. I. (1991), Biological and genetic contributors to violence: Widom's untold tale. Psychological Bulletin, 109(1), pp. 125-129.

Dyregrov A., Gjestad R., Gupta L., Mukanoheli E., (2000), Trauma exposure and psychological reactions to genocide among rwandan children. Journal of Traumatic Stress, 15, pp. 59-68.

Ebbinghaus H., (1885), Memory: A Contribution to Experimental Psychology, Translated by Henry A. Ruger \& Clara E. Bussenius, 1913. Originally published in New York by Teachers College, Columbia University, NY.

Emery R. E., Laumann-Billings L., (1998), An overview of the nature, causes, and consequences of abusive family relationships: Toward differentiating maltreatment and violence, American Psychologist, Vol. 53(2), (Feb.), pp. 121-135.

Endres J., (1997), The suggestibility of the child witness: the role of individual differences and their assessment, in The Journal of Credibility Assessment and Witness Psychology, 1, 2, pp. 44-67.

Everson M.D., (1997), Elementi strani, improbabili e fantastici nei racconti dei minori, Maltrattamento e Abuso all'infanzia, n. 1(1), pp. 19-58.

Fergusson D. M., Mullen P. E., (1999), Childhood sexual abuse: an evidence based perspective. Sage Publications, Thousand Oaks, CA.

Finkelhor D., (1979), What's Wrong with Sex Between Adults and Children? American Journal of Orthopsychiatry, Vol 49(4), (Oct), pp. 692-697.

Galton F. (1883), Inquiries into Human Faculty and its Development. AMS Press, New York.

Galvin M. R., Stilwell B. M., Shekhar A., Kopta S.M., Goldfarb S. M., (1997), Maltreatment, conscience functioning and dopamine beta hydroxylase in emotionally disturbed boys. Child Abuse Negl. 21: 83-92.

Garven S., Wood J. M., Malpass R. S. \& Shaw J. S., (1998), More than suggestion: The effect of interviewing techniques from the McMartin Preschool case. Journal of Applied Psychology, 83, pp. 347-359.

Giannini A. M., Giusberti F., (2009), La testimonianza del minore, website Associazione Italiana di Psicologia AIP, 17/10/2009.

Goldson E., Fitch M. J., Wendell T., Knapp G., (1978), Abuso di minori: rapporto tra peso alla nascita, punteggio apgar e test di sviluppo. Am J Dis Child, Pediatr. Neurosur.; 132: 790-793.

Goodman G. S., \& Schwartz-Kenney B. M., (1992), Why knowing a child's age is not enough: Effects of cognitive, social, and emotional factors on children's testimony. In R. Flin \& H. Dent (Eds.), Children as witnesses, Wiley, London, pp. 15-32.

Gudjonsson G. H., (1992), The Psychology of Interrogations, Confessions, and Testimony. John Wiley \& Sons, xii ed. New York, p. 362.

Gudjonsson G. H., (1992a), Interrogative suggestibility: Factor analysis of the Gudjonsson Suggestibility Scale (GSS 2). In Personality and Individual Differences, 13, pp. 479-481.

Harter S., (1983), Developmental perspectives on the self-system. In E. M. Hetherington (Ed.), Handbook of child psychology. John Wiley. New York, pp. 275-385.

Hermann J. L., (1992a), Complex PTSD: A syndrome in survivors of prolonged and repeated trauma. In Journal of Traumatic Stress, 5,3 .

Horowitz M. J., (1976), Stress response syndromes, Jason Aronson, New York.

Hunter I. M. L., (1957), Memory. Penguin, London.

Janet P., (1889), L'Automatisme psychologique, Félix Alcan, Paris. Reprint: Société Pierre Janet, Paris (1973).
Johnson M. K., Hashtroudi S., \& Lindsay D. S, (1993), Source monitoring. Psychological Bulletin, 114, pp. 3-28.

Kaufman J., Zigler E., (1987), Do abused children become abusive parents? Am J Orthopsychiatry, (Apr); 57(2): 186-192.

Keenan J. M., \& Baillet S. D., (1980), Memory for personally and socially significant events. In R. S. Nickerson (Ed.), Attention and performance, VIII ed., Lawrence Erlbaum, Hillsdale, N.J.

Kempe C. H., (1978), Sexual Abuse, Another Hidden Pediatric Problem. In Pediatrics, 62, 382.

Kempe R. S., Kempe H., (1978), Child Abuse: The Developing Child, Open Books, UK.

Kuterovac-Jagodiç G., (2003), Post-traumatic stress symptoms in croatian children exposed to war: A prospective study. Journal of Clinical Psychology, 59, pp. 9-25.

Liotti G., (2001), Le opere della coscienza: Psicopatologia e psicoterapia nella prospettiva cognitivo-evoluzionista. Raffaello Cortina Editore, Milano.

Liotti G., (2013), Phobias of attachment-related states in the psychotherapy of adult survivors of childhood complex trauma. Journal of Clincal Psychology. 69, pp. 1136-1147.

Lipmann O., (1911), Pedagogical psychology of report. Journal of Educational Psychology, 2, pp. 253-261.

Liotti G., Farina B., (2011), Sviluppi traumatici, Raffaello Cortina Editore, Milano.

Loftus, E.F., (1979), Eyewitness testimony, Cambridge University Press, Cambridge, MA.

Loftus E. F., (1989), Misinformation and memory: The creation of new memories. Journal of Experimental Psychology: General. Vol 118(1), (Mar), pp. 100-104.

Loftus E. F., (1997), Creating False Memories. In Scientific American (October) 277(3): 70-5.

Loftus E. F., Burns T. E., (1982), Mental shock can produce retrograde amnesia. In Memory \& Cognition, July, Vol. 10, Issue 4, pp. 318-323.

Loftus E. F., Davies G. M., (1984), Distortion in the memory of children, Journal of Social Issue, pp. 40, 51-67.

Loftus E. F., \& Ketcham K., (1994), The Myth of Repressed Memory. St. Martin's Press, NY.

Loftus E. F., Miller D. G., Burns H. J., (1978), Semantic Integration of Verbal Information into a Visual Memory. Journal of Experimental Psychology; Human Learning and Memory. Vol. 4, No. 1, pp. 19-31.

Loftus E. F., \& Palmer J. C., (1974), Reconstruction of automobile destruction: An example of the interaction between language and memory. Journal of verbal learning and verbal behavior, 13(5), pp. 585-589.

Loftus E. F., Pickrell J., (1995), The formation of false memories, Psychiatric Annals, 25, pp. 720-724.

Loftus E. F., Schooler J. W., Boone S. M., \& Kline D., (1987), Time went by so slowly: Overestimation of event duration by males and females. Applied Cognitive Psychology, 1, pp. 3-13.

Macksound M. S., Aber J. L., (1986), The war experiences and psychosocial development of children in Lebanon. Child Development, 67, p. 70.

Malacrea M., (1998), Trauma e riparazione. Cortina, Milano.

Malinovsky-Rummel R., \& Hansen D. J., (1993), Long-term consequences of childhood physical abuse. Psychological Bulletin, 14 (10), pp. 68-79.

Mastronardi V., (2012), Manuale per operatori criminologici e psicopatologi forensi, Giuffrè Editore, V Edizione, Milano, pp. 355-359.

Mazzoni G., (1995), Suggestionabilità nella testimonianza: a età diverse corrispondono meccanismi diversi, Età Evolutiva, 52, pp. 83-90. 
Mazzoni G., (1999), Abusi sessuali. I bambini raccontano, Psicologia contemporanea, 151, pp. 4-11.

Mazzoni G., (2000), La testimonianza nei casi di abuso sessuale sui minori, Giuffrè Editore, Milano, pp. 27-28.

Mazzoni G., Loftus E. F., (1998), in J. De Rivera, T. E. Sarbin (Eds.), Believed-In imagining: The narrative construction of reality, APA Press, Washington D.C.

McLeer S.V., Deblinger E., Henry D., Orvaschel H., (1992), Sexually abused children at high risk for post-traumatic stress disorder, J Am Acad Child Adolesc Psychiatry, (Sep); 31(5): $875-9$.

McNally R. J., (1991), Assessment of post-traumatic stress disorder in children. Psychological Assessment, 3: 531-537.

Montecchi F., (1994), Gli abusi all'infanzia. Dalla ricerca all'intervento clinico, Carocci Editore, Roma.

Musatti C. L., (1991), Elementi di psicologia della testimonianza. Rizzoli, Milano.

Nader K., Bechara A., van der Kooy D., (1997), Neurobiological constraints on behavioral models of motivation. Annu Rev Psychol.; 48: 85-114.

Ornitz E. M., Pynoos R. S.,(1989), Startle modulation in children with posttraumatic stress disorder. Am J Psychiatry, 146 (1989), pp. 866-870.

Paardekooper B., de Jong J. T. V. M., Hermanns J. M. A., (1999), The psychological impact of war and the refugee situation on South Sudanese children in refugee camps in Northern Uganda: An exploratory study. Journal of Child Psychology and Psychiatry, 40, pp. 529-536.

Pavlov I. P., (1927), Conditioned reflexes: an investigation of the physiological activity of the cerebral cortex. Oxford Univ. Press, Oxford, England.

Pescina D., (2007), I falsi ricordi: il paradigma DRM applicato alle immagini. Rassegna di Psicoterapie. Ipnosi. Medicina Psicosomatica. Psicopatologia Forense. Periodico quadrimestrale a carattere scientifico Università degli Studi di Roma "La Sapienza", Volume 12 - N. 3, (Settembre-Dicembre).

Pescina D., (2008), La testimonianza e i falsi ricordi. Ricerca sperimentale. Rassegna di Psicoterapie. Ipnosi. Medicina Psicosomatica. Psicopatologia Forense. Periodico quadrimestrale

Correspondence: Francesca Romana Ficorilli.

E-mail: francescaromana.ficorilli@gmail.com

Key words: Trauma; sexual abuse; memory and testimony; suggestibility and false memories; EMDR.

Parole chiave: Trauma; abuso sessuale; memoria e testimonianza; suggestionabilità e falsi ricordi; EMDR.

Palabras clave: Trauma; abuso sexual; memoria y testimonio; sugestionabilidad y falsos recuerdos; MDR.

Received for publication: 10 August 2018.

Revision received: 20 September 2018.

Accepted for publication: 25 October 2018.

This article is distributed under the terms of the Creative Commons Attribution Noncommercial License (by-nc 4.0) which permits any noncommercial use, distribution, and reproduction in any medium, provided the original author(s) and source are credited.

(C) Copyright F.R. Ficorilli, 2018

Licensee PAGEPress, Italy

Rivista di Psicopatologia Forense, Medicina Legale, Criminologia

2018; $23: 41$

doi:10.4081/psyco.2018.41 a carattere scientifico Università degli Studi di Roma "La Sapienza", Volume 13 - N. 2, (Maggio-Agosto).

Pollak S. D., Cicchetti D., Klorman R., Brumaghin J. T., (1997), Cognitive brain event-related potentials and emotion processing in maltreated children. Child Development, 68, pp. 773-787.

Russell D. E. H., (1983), The incidence and prevalence of intrafamilial and extrafamilial sexual abuse, Child Abuse and Neglect, 7, 2, pp. 133-146.

Schacter D. L., (1992), Understanding Implicit Memory: A Cognitive Neuroscience Approach. American Psychologist, 47(4), pp. 559-569.

Schore, A. N., (2003), Affect dysregulation and disorders of the self. Norton, New York.

Schore A. N., (2009a), Relational trauma and the developing right brain: The neurobiology of broken attachment bonds, Routledge, London.

Schooler, J.W., Loftus, E.F., (1986), Individual differences and experimentation: complementary approaches to interrogative suggestibility. In Social Behavior, 1, pp. 105-112.

Servan-Schreiber D., Le Lin B., Birmaher B., (1998), Prevalence of posttraumatic stress disorder and major depressive disorder in Tibetan refugee children. J Am Acad Child Adolesc Psychiatry. (Aug); 37(8): 874-9.

Shallice T., (1988), From Neuropsychology to Mental Structure. Cambridge University Press, New York.

Shapiro F., (1989), Eye movement desensitization: a new treatment for post-traumatic stress disorder. J Behav Ther Exp Psychiatry, Sep; 20(3): 211-7.

Shapiro F., (2013), The Role of Eye Movement Desensitization and Reprocessing (EMDR) Therapy in Medicine: Addressing the Psychological and Physical Symptoms Stemming from Adverse Life Experiences. The Permanent Journal,Winter; 18(1): 71-77.

Siegel D. J., (1999), La mente relazionale. Neurobiologia dell'esperienza interpersonale, Cortina Raffaello, Milano.

Stern W., (1910), Abstracts of lectures on the psychology of testimony and on the study of individuality. In American Journal of Psychology, 21, pp. 270-282.

Stroop J. R., (1995), Studies of interference in serial verbal reactions. Journal of Experimental Psychology, 18, pp. 643-662.

Thabet A. A. M., Abed Y., Vostanis P., (2004 ), Comorbidity of PTSD and depression among refugee children during war conflict. Journal of Child Psychology and Psychiatry, 45, pp. 533-544.

Tulving E., (1972), Episodic and semantic memory. In E. Tulving and W. Donaldson (Eds.), Organization of Memory, Academic Press, New York, pp. 381-402.

Tulving E., Thomson D. M., (1973), Encoding specificity and retrieval processes in episodic memory. In Psychological Review, 80, pp. 352-373.

van der Hart O., Nijenhuis E. R. S., \& Steele K., (2011), Fantasmi nel sé. Trauma e trattamento della dissociazione strutturale. Raffaello Cortina, Milano.

van der Kolk B. A., (1994), The body keeps the score: Memory and the evolving psychobiology of posttraumatic stress. In Harvard Review of Psychiatry, Jan-Feb 1(5), pp. 253-265.

van der Kolk B. A., (2005), Developmental trauma disorder: Toward a rational diagnosis for children with complex trauma histories. Psychiatric Annals, 35, 5, pp. 401-408.

Varendonck J., (1911), Les temoignages d'enfant dans un process retentissant, Archives de Psychologie, 11, pp. 129-171.

Winnicott D. W., (1971), Gioco e realtà. A. Armando, Roma 1974.

Yerkes R. M., Dodson J. D., (1908), The Relation Of Strength Of Stimulus To Rapidity Of Habit-Formation. In Journal of Comparative Neurology and Psychology, 18, pp. 459-482. 